\title{
Experimental investigation of the impact of compound-specific dispersion and electrostatic interactions on transient transport and solute breakthrough
}

\author{
Muniruzzaman, Muhammad; Rolle, Massimo
}

Published in:

Water Resources Research

Link to article, DOI:

10.1002/2016WR019727

Publication date:

2017

Document Version

Publisher's PDF, also known as Version of record

Link back to DTU Orbit

Citation (APA):

Muniruzzaman, M., \& Rolle, M. (2017). Experimental investigation of the impact of compound-specific dispersion and electrostatic interactions on transient transport and solute breakthrough. Water Resources Research, 53(2), 1189-1209. https://doi.org/10.1002/2016WR019727

\section{General rights}

Copyright and moral rights for the publications made accessible in the public portal are retained by the authors and/or other copyright owners and it is a condition of accessing publications that users recognise and abide by the legal requirements associated with these rights.

- Users may download and print one copy of any publication from the public portal for the purpose of private study or research.

- You may not further distribute the material or use it for any profit-making activity or commercial gain

- You may freely distribute the URL identifying the publication in the public portal 


\section{Water Resources Research}

\section{RESEARCH ARTICLE \\ 10.1002/2016WR019727 \\ Key Points: \\ Experimental investigation of the impact of compound-specific dispersion and electrostatic interactions on transient transport and solute breakthrough}

- Investigation of 2-D transient transport with high-resolution multitracer and multicomponent ionic flow-through experiments - Distinct breakthrough curves of different conservative solutes in strongly advection-dominated flows - Both spreading and mixing depend on tracer diffusion and chargeinduced Coulombic interactions

Supporting Information: - Supporting Information S1

Correspondence to:

M. Rolle,

masro@env.dtu.dk

Citation:

Muniruzzaman, M., and M. Rolle (2017), Experimental investigation of the impact of compound-specific dispersion and electrostatic interactions on transient transport and solute breakthrough, Water Resour. Res., 53, 1189-1209, doi:10.1002/ 2016WR019727.

Received 31 AUG 2016 Accepted 6 JAN 2017

Accepted article online 13 JAN 2017 Published online 3 FEB 2017

(c) 2017. American Geophysical Union. All Rights Reserved.

\author{
Muhammad Muniruzzaman ${ }^{1}$ (D) and Massimo Rolle ${ }^{1,2}$ (iD) \\ ${ }^{1}$ Center for Applied Geosciences, University of Tübingen, Tübingen, Germany, ${ }^{2}$ Department of Environmental \\ Engineering, Technical University of Denmark, Lyngby, Denmark
}

\begin{abstract}
This study investigates the effects of compound-specific diffusion/dispersion and electrochemical migration on transient solute transport in saturated porous media. We conducted laboratory benchscale experiments, under advection-dominated regimes (seepage velocity: $0.5,5,25 \mathrm{~m} / \mathrm{d}$ ), in a quasi two-dimensional flow-through setup using pulse injection of multiple tracers (both uncharged and ionic species). Extensive sampling and measurement of solutes' concentrations ( $\sim 1500$ samples; $>3000$ measurements) were performed at the outlet of the flow-through setup, at high spatial and temporal resolution. The experimental results show that compound-specific effects and charge-induced Coulombic interactions are important not only at low velocities and/or for steady state plumes but also for transient transport under high flow velocities. Such effects can lead to a remarkably different behavior of measured breakthrough curves also at very high Péclet numbers. To quantitatively interpret the experimental results, we used four modeling approaches: classical advection-dispersion equation (ADE), continuous time random walk (CTRW), dual-domain mass transfer model (DDMT), and a multicomponent ionic dispersion model. The latter is based on the multicomponent formulation of coupled diffusive/dispersive fluxes and was used to describe and explain the electrostatic effects of charged species. Furthermore, we determined experimentally the temporal profiles of the flux-related dilution index. This metric of mixing, used in connection with the traditional solute breakthrough curves, proved to be useful to correctly distinguish between plume spreading and mixing, particularly for the cases in which the sole analysis of integrated concentration breakthrough curves may lead to erroneous interpretation of plume dilution.
\end{abstract}

\section{Introduction}

Conservative transport in porous media is determined by fundamental physical (e.g., aqueous diffusion, advection) and/or electrochemical (e.g., Coulombic effects, ion-pairing, charge coupling) processes [e.g., Gvirtzman and Gorelick, 1991; Kitanidis, 1994; Haggerty and Gorelick, 1995; Boudreau, 1997; Thullner et al., 2005; Appelo and Wersin, 2007; Steefel and Maher, 2009]. Dilution and mixing are among the most important mechanisms controlling solute transport in porous media [e.g., Dentz et al. 2011; Le Borgne et al., 2011]. In particular, these mechanisms are ultimately controlled by small-scale processes such as diffusion and localscale dispersion [e.g., Chiogna et al., 2011; Cirpka et al., 2011]. Numerous studies focusing on experimental and numerical investigations have contributed to the increased recognition that aqueous diffusion, which is the only true mixing process in groundwater [Kitanidis, 1994], quantitatively plays an important role on macroscale solute transport in porous media [e.g., Carrera et al., 1998; LaBolle and Fogg, 2001; Chiogna et al., 2010; Zhang et al., 2010; Fiori et al., 2011; Haberer et al., 2011; Molins et al., 2012; Rolle et al., 2013a; Hadley and Newell, 2014]. Recent experiments and pore-scale simulations showed the key effects of incomplete mixing in the pore channels on the observed macroscopic transport behavior [e.g., Raje and Kapoor, 2000; Gramling et al., 2002; Tartakovsky et al., 2009] and have triggered the development of new transport formulations and modeling approaches [e.g., Willmann et al., 2008; Edery et al., 2009; Sanchez-Vila et al., 2010; Chiogna and Bellin, 2013; Porta et al., 2015]. Incomplete mixing is due to the slow rate of diffusion, which allows concentration gradients to be sustained at the small scale [Cao and Kitanidis, 1998; Rolle et al., 2012]. In the study of transverse mixing, such effects were found to be responsible for the nonlinear dependence of the mechanical dispersion term on the average flow velocity, as well as on its direct dependence on the 
solute diffusivity also in advection-dominated regimes [e.g., Chiogna et al., 2010; Rolle et al., 2012; Scheven, 2013; Hochstetler et al., 2013]. An aspect that has been investigated in the geochemical literature [Vinograd and McBain, 1941; Felmy and Weare, 1991; Van Cappellen and Gaillard, 1996; Giambalvo et al., 2002; Liu, 2007; Appelo et al., 2008; Steefel and Maher, 2009], but that is not often considered in subsurface hydrology studies is that, besides diffusion, also electrostatic interactions affect the movement of charged solutes (e.g., major ions and many inorganic and organic contaminants) in groundwater. The capability to capture, accurately describe, and properly upscale the effects of controlling small-scale processes on macroscopic transport is of primary importance to further develop and advance the current descriptions and formulations of solute transport in porous media. To this end, controlled laboratory experiments are instrumental to provide high-resolution data necessary to test and validate different modeling approaches. Despite a wealth of experimental data have been collected over decades in laboratory flow-through systems and particularly in 1-D column setups [e.g. Delgado, 2006], multidimensional and multitracer transient experiments with depth-resolved measurements are rare. Although it might be argued that depth-integrated measurements are more convenient and representative of common practice, they are not ideal to understand transport and mixing processes [Cirpka and Kitanidis, 2000]. In particular, if the goal is to characterize the effects of small-scale diffusive processes on transient solute transport, depth-resolved measurements of solute concentrations (and volumetric fluxes) are necessary.

The main objective of this study is to provide a detailed experimental investigation of transient transport in saturated porous media and, specifically, to explore the effects of compound-specific and electrostatic interactions. We performed laboratory bench-scale experiments in homogeneously packed quasi 2-D setups under advection-dominated regimes. In particular, we simultaneously injected multiple tracers (both "charge-neutral" and "charged" species) to identify the effects of compound-specific diffusion/dispersion, pore-scale incomplete mixing, and electrostatic interactions on plume dilution and spreading. The injection of a small pulse facilitates establishing "fully 2-D" transient plumes that mix with the surrounding water. The plumes' breakthrough at the outlet was measured at high spatial and temporal resolution. Such sampling approach allows characterizing both longitudinal and transverse evolution of the tracers' plumes. We determined experimentally an entropy-based metric of mixing, the flux-related dilution index, from concentrations and flow rates measurements. Temporal profiles of this quantity were helpful for the interpretation of the integrated flux-weighted breakthrough curves and to help distinguishing between plume spreading and dilution. The concentration breakthrough curves were quantitatively analyzed with different transport models: classical advection-dispersion model (ADE), continuous time random walk (CTRW), and dualdomain mass transfer model (DDMT). The electrostatic behavior of multicomponent ionic tracers was explained by using a forward model based on a Nernst-Planck formulation including the coupling of dispersive fluxes. Both experimental and model outcomes show that the aqueous diffusion and the electrostatic interactions can significantly impact the macroscale transient transport and can lead to remarkably different behaviors under strongly advection-dominated regimes. Our experimental dataset also represents a challenge, as well as an opportunity of further development, for the different solute transport models. In fact, despite individual fits could reproduce the measured concentrations, generalized formulations able to consistently capture all experimental conditions will need to be developed.

\section{Experimental Setup}

Laboratory experiments were performed to investigate transient solute transport, as well as plume dilution in a quasi 2-D flow-through system. The experimental setup consists of an acrylic-glass chamber which has inner dimensions of $100 \mathrm{~cm} \times 19 \mathrm{~cm} \times 1 \mathrm{~cm}(\mathrm{~L} \times \mathrm{H} \times \mathrm{W})$. The flow-through chamber is equipped with 24 equally spaced ( $5 \mathrm{~mm}$ spacing) ports at both inlet and outlet ends (Figure 1). At each end, these injection (inlet) and extraction (outlet) ports are directly connected to a 24 channel high-precision peristatic pump (ISMATEC IPC-N24, Ismatec, Glattburg, Switzerland) through Fluran HCA pump tubings (ID $0.64 \mathrm{~mm}$; Ismatec, Glattburg, Switzerland). The flow-through setup was homogeneously packed with glass beads with a grain size diameter of 1.00-1.50 mm (Sartorius AG, Göttingen, Germany). In order to avoid possible air entrapment in the water-saturated porous medium, a wet-packing procedure was followed in the packing step [e.g., Haberer et al., 2012]. The peristaltic pumps were used to obtain a uniform horizontal fluid flow in the porous medium. Before each experiment, both inlet and outlet pumps were calibrated and the experiments 


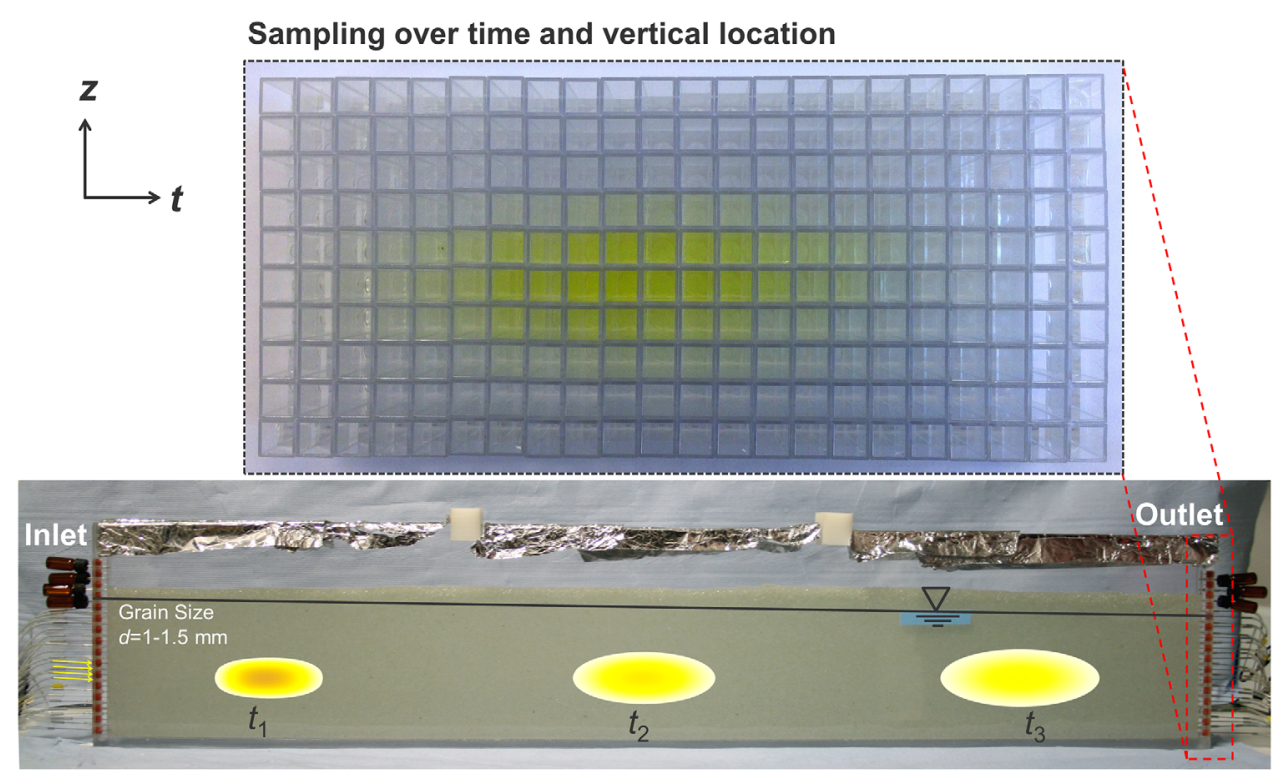

Dimensions, $L \times W \times H: 100[\mathrm{~cm}] \times 19[\mathrm{~cm}] \times 1[\mathrm{~cm}]$

Figure 1. Laboratory flow-through setup with the schematic illustration of the temporal evolution of a tracer plume injected from the four central inlet ports. The inset shows a photograph of fluorescein samples collected at different vertical locations at the outlet as a function of time.

were performed in a temperature controlled room $\left(T=20^{\circ} \mathrm{C}\right)$. Figure 1 illustrates the experimental setup, as well as an example of high-resolution sampling at the outlet ports.

The experiments were initiated by establishing a steady water flow by flushing the domain with at least two pore volumes. When the flow-condition was completely stable over time, we started the transport experiments by injecting the tracer solutions through the four central inlet ports (port number 10, 11, 12, and 13; corresponding to the vertical locations of 5, 5.5, 6 , and $6.5 \mathrm{~cm}$ from the bottom of the chamber, respectively). All tracer experiments were performed by applying a pulse input at the inlet boundary for a finite duration. To ensure similar injection conditions in the different experiments, we inject the tracer solutions for the duration of $\sim 0.05$ pore volumes. Afterward, samples were taken at all the outlet extraction ports at regular time intervals. Such sampling strategy allowed us to measure high-resolution temporal and spatial profiles at the outlet of the flow-through system. Additionally, we determined the volumetric water flux in each extraction port by collecting and weighing the effluent for a given period of time. Details of the experimental settings are reported in Table 1.

Table 1. Summary of Geometry and Transport Parameters of the Experimental System

Experimental settings

Setup dimensions $(\mathrm{L} \times \mathrm{H} \times \mathrm{W})(\mathrm{cm})$

Number of inlet/outlet ports used

Port spacing $(\mathrm{mm})$

Grain diameter of porous matrix $(\mathrm{mm}) \quad 1.00-1.50$

Seepage velocity $(\mathrm{m} / \mathrm{d}) \quad 0.5,5,25$

Average porosity

Diffusion coefficients

$\mathrm{Na}^{+}$

$\mathrm{K}^{+}$

$\mathrm{Mg}^{2+}$

$\mathrm{Cl}^{-}$

$\mathrm{Br}^{-}$

Fluorescein ${ }^{\mathrm{b}}$

${ }^{a}$ Values from Lasaga [1998] at $18^{\circ} \mathrm{C}$, and corrected for temperature and viscosity changes at $20^{\circ} \mathrm{C}$ (experimental conditions).

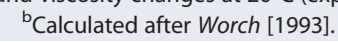

In this work, we performed two types of experiments to explore the behavior of different tracers: (i) multitracer experiments, and (ii) multicomponent ionic experiments. Multitracer experiments were conducted at three distinct nominal seepage velocities of $0.5,5$, and $25 \mathrm{~m} /$ d. Solutions containing potassium chloride (30$136 \mathrm{mg} / \mathrm{L}$ ) and sodium fluorescein (27-102 mg/ L) were used as tracer solutions; whereas ultrapure Milli-Q water (Labostar 1-DI, Evoqua, USA) was used as background solution. The aqueous diffusivities of the different solutes vary considerably and are reported in Table 1. Multicomponent ionic experiments were performed to show the relevance of electrostatic effects during transient transport in multi-ionic environments. In these experiments, a pulse of $1: 2$ 


\begin{tabular}{|c|c|c|c|c|c|c|}
\hline Experiments & Tracer Cor & ncentrations & $\begin{array}{l}\text { Pulse } \\
\text { Duration } \\
\text { (min) }\end{array}$ & $\begin{array}{l}\text { Sampling } \\
\text { Intervals } \\
\text { (min) }\end{array}$ & $\begin{array}{c}\text { No. of } \\
\text { Samples }\end{array}$ & $\begin{array}{c}\text { No. of } \\
\text { Measurements }\end{array}$ \\
\hline \multicolumn{7}{|l|}{ Multitracer experiments } \\
\hline & Fluorescein (mg/L) & $\mathrm{KCl}(\mathrm{mg} / \mathrm{L})$ & & & & \\
\hline$v \approx 0.5 \mathrm{~m} / \mathrm{d}\left(P e_{\mathrm{Cl}^{-}}=4, P e_{\text {Fluor }}=16\right)$ & 27 & 30 & 165 & 50 & 260 & 520 \\
\hline$v \approx 5 \mathrm{~m} / \mathrm{d}\left(P e_{\mathrm{Cl}^{-}}=40, P e_{\mathrm{Fluor}}=161\right)$ & 101.6 & 136.2 & 15 & 5 & 300 & 600 \\
\hline$v \approx 25 \mathrm{~m} / \mathrm{d}\left(P e_{\mathrm{Cl}^{-}}=200, P e_{\text {Fluor }}=804\right)$ & 35.9 & 40.7 & 3 & 1 & 270 & 540 \\
\hline \multicolumn{7}{|c|}{ Multicomponent ionic experiments $(v \approx 5 \mathrm{~m} / \mathrm{d}$ ) } \\
\hline & Tracer $\left(\mathrm{MgCl}_{2}\right)$ & Background solution & & & & \\
\hline (a) in pure water & $0.80 \mathrm{mM}$ & Milli-Q water & 15 & 5 & 300 & 600 \\
\hline (b) in a buffer electrolyte solution & $0.80 \mathrm{mM}$ & $\mathrm{NaBr}(4.04 \mathrm{mM})$ & 15 & 5 & 300 & 1200 \\
\hline
\end{tabular}

electrolyte solution (magnesium chloride; $0.80 \mathrm{mM}$ ) was injected into the saturated porous medium. As background solution, either Milli-Q water or $\mathrm{NaBr}$ solution (1:1 electrolyte; $4.04 \mathrm{mM}$ ) was used for these experiments (Table 2). The multicomponent ionic experiments were performed at a flow velocity of $\sim 5 \mathrm{~m} / \mathrm{d}$.

The samples collected at the outlet ports were analyzed to determine the concentration of the different solutes. Fluorescein concentration was measured by using a UV-spectrophotometer (DR 2800, Hach, Germany). The extinction and emission wavelengths were 483 and $515 \mathrm{~nm}$, respectively. The anion concentrations $\left(\mathrm{Cl}^{-}\right.$, $\mathrm{Br}^{-}$) were measured by ion-chromatography (Dionex ICS-1500, Thermo Scientific, USA); whereas the cations $\left(\mathrm{Mg}^{2+}\right.$ and $\mathrm{Na}^{+}$) were measured by ICP-MS (Agilent 7700 Series, Agilent Technologies, Japan). Table 2 summarizes important experimental conditions, as well as details on the sampling procedure.

\section{Modeling Approach and Data Evaluation}

Four different solute transport models were used to interpret the results of the multitracer experiments. This section summarizes the main equations of these models and the data evaluation approaches. Further details about the different models are provided in supporting information.

\subsection{Analysis of Breakthrough Curves (BTCs)}

3.1.1. Advection-Dispersion Equation (ADE)

The analytical solution of the 2-D advection-dispersion equation, subjected to a pulse input of the tracer along a line source for a finite duration, is given by [e.g., Leij et al., 1991; van Genuchten et al., 2013]:

$$
C(x, z, t)=\frac{C_{0}}{2} \int_{P(t)}^{t} \frac{x}{\tau}\left[\left\{\frac{1}{\sqrt{4 \pi D_{L} \tau}} \exp \left(-\frac{(x-v \tau)^{2}}{4 D_{L} \tau}\right)\right\} \cdot\left\{\operatorname{erfc}\left(\frac{z-w / 2}{\sqrt{4 D_{T} \tau}}\right)-\operatorname{erfc}\left(\frac{z+w / 2}{\sqrt{4 D_{T} \tau}}\right)\right\}\right] d \tau
$$

where

$$
P(t)=\left\{\begin{array}{lll}
0 & \text { when } 0<t \leq t_{0} \\
t-t_{0} & \text { when } t>t_{0}
\end{array}\right.
$$

where $C\left[\mathrm{M} / \mathrm{L}^{3}\right]$ is the concentration of the solute, $v[\mathrm{~L} / T]$ is the seepage velocity, $D_{L}\left[\mathrm{~L}^{2} / \mathrm{T}\right]$ and $D_{T}\left[\mathrm{~L}^{2} / T\right]$ are longitudinal and transverse hydrodynamic dispersion coefficients, respectively, $x[\mathrm{~L}]$ and $z[\mathrm{~L}]$ are the spatial coordinates in the directions parallel and orthogonal to the principal flow direction, and $t[T$ denotes the time. $w[L]$ denotes the source width at the inflow, $C_{0}\left[\mathrm{M} / \mathrm{L}^{3}\right]$ is the inflow concentration, and $t_{0}[T]$ is the duration of the pulse.

For the analysis of breakthrough curves, a 1-D model is convenient and it becomes necessary when only vertically integrated measurements are available. The analytical solution for 1-D transport problem for the equivalent boundary and initial conditions reads as [e.g., van Genuchten et al., 2013]:

$$
C(x, t)=\frac{C_{0}}{2}\left[\left\{\operatorname{erfc}\left(\frac{x-v t}{\sqrt{4 D_{L} t}}\right)-\operatorname{erfc}\left(\frac{x-v\left(t-t_{0}\right)}{\left.\sqrt{4 D_{L}(t}-t_{0}\right)}\right)\right\}+\exp \left(\frac{v x}{D_{L}}\right)\left\{\operatorname{erfc}\left(\frac{x+v t}{\sqrt{4 D_{L} t}}\right)-\operatorname{erfc}\left(\frac{x+v\left(t-t_{0}\right)}{\left.\sqrt{4 D_{L}(t}-t_{0}\right)}\right)\right\}\right]
$$

This simplified 1-D analytical solution agrees very well with the full 2-D analytical solution of equation (1) when the mass-fluxes at a specific cross section are vertically integrated and normalized by the integrated mass-flux 
at the inflow boundary (supporting information Figure S1). We denote this spatially integrated quantities as "boundary-normalized integrated breakthrough curves" or, for simplicity, just "integrated BTCs" $\left(\left.\hat{C}(x, t)\right|_{B N} ^{B T C}\right)$ :

$$
\left.\hat{C}(x, t)\right|_{B N} ^{B T C}=\frac{\int_{-\infty}^{\infty} C(x, z, t) q_{x}(z) d z}{\int_{-\infty}^{\infty} g(z, t) q_{x}(z) d z}
$$

where $q_{x}[\mathrm{~L} / \mathrm{T}]$ is the specific discharge in the longitudinal direction, and $g(z, t)$ is the inlet boundary condition (equation (S2), supporting information). We used this 1-D solution (equation (2)) to fit the breakthrough curves measured at each individual outlet ports (local BTC), as well as the integrated BTCs (equation (3)).

\subsubsection{Non-Fickian Transport Models}

In order to investigate the "non-Fickian" or "anomalous" behavior of tracer plumes studied in our experiments, we used continuous time random walk (CTRW) and dual-domain mass transfer model (DDMT). The CTRW transport equation in partial differential equation form reads as [e.g., Berkowitz et al., 2006; Berkowitz and Scher, 2009; Heidari and Li, 2014]:

$$
\frac{\partial c(\mathbf{s}, t)}{\partial t}=-\int_{0}^{t} M\left(t-t^{\prime}\right)\left[\mathbf{v}_{\psi} \cdot \nabla c\left(\mathbf{s}, t^{\prime}\right)-\mathbf{D}_{\psi}: \nabla \nabla c\left(\mathbf{s}, t^{\prime}\right)\right] d t^{\prime}
$$

in which $c(\mathbf{s}, t)$ is the concentration, $\mathbf{v}_{\psi}$ and $\mathbf{D}_{\psi}$ are the transport velocity and generalized dispersion coefficient, respectively. $M(t)$ is a memory function which accounts for the unknown, small-scale heterogeneities beyond the level of experimental detection [Cortis and Berkowitz, 2005; Kosakowski et al., 2001]. This memory function can take any possible form depending on the functional form of probability rate for transition time $(\tilde{\psi}(u))$. The truncated power law (TPL) form of $\tilde{\psi}(u)$ is written as:

$$
\tilde{\psi}(u) \equiv\left(1+\tau_{2} u t_{1}\right)^{\beta} \exp \left(t_{1} u\right) \frac{\Gamma\left(-\beta, \tau_{2}^{-1}+t_{1} u\right)}{\Gamma\left(-\beta, \tau_{2}^{-1}\right)} \quad 0<\beta<2
$$

where $t_{1}$ and $t_{2}$ (with $\tau_{2} \equiv t_{2} / t_{1}$ ) are the lower and upper limits of power law behavior, respectively, $u$ is the Laplace variable, and $\boldsymbol{\Gamma}$ is incomplete gamma function. $\beta$ is a measure of the extent of "non-Fickian" or "anomalous" nature of transport with values between 0 and 2 representing the non-Fickian behavior.

The transport equations for DDMT for a first-order exchange in 1-D domain are given by [e.g., van Genuchten and Wierenga, 1976; Valocchi, 1985; Gorelick et al., 2005; Luo et al. 2005, 2007]:

$$
\begin{gathered}
\eta_{m} \frac{\partial C_{m}}{\partial t}+\eta_{i m} \frac{\partial C_{i m}}{\partial t}+q \frac{\partial C_{m}}{\partial x}-\eta_{m} \frac{\partial}{\partial x}\left(D_{L}^{m} \frac{\partial C_{m}}{\partial x}\right)=0 \\
\eta_{i m} \frac{\partial C_{i m}}{\partial t}=\xi\left(C_{m}-C_{i m}\right)
\end{gathered}
$$

where the indices $m$ and $i m$ refer to the mobile and immobile domains, respectively. $C_{m}\left[\mathrm{M} / \mathrm{L}^{3}\right]$ and $C_{i m}$ $\left[\mathrm{M} / \mathrm{L}^{3}\right]$ are the concentrations in mobile and immobile domain; $\eta_{m}$ and $\eta_{i m}$ are the mobile and immobile porosities, respectively; $q[\mathrm{~L} / \mathrm{T}]$ denotes the specific discharge; and $\xi[1 / \mathrm{T}]$ is the mass transfer coefficient.

\subsubsection{Optimization Procedure}

In order to fit the different models to the experimental data, the following objective function was considered:

$$
\chi^{2}=\sum_{i=1}^{N_{\text {meas }}}\left(C_{i}^{\text {meas }}-C_{i}^{\text {mod }}\right)^{2}
$$

where $N_{\text {meas }}$ is the number of data points, $C_{i}^{\text {meas }}$ represents the normalized measured concentrations, and $C_{i}^{\text {mod }}$ represents the normalized model predicted concentrations. For the fitting of breakthrough curves with the ADE model, seepage velocity $(v)$ and dispersion coefficient $\left(D_{L}\right)$ were considered as fitting parameters. In CTRW fitting, we considered both transport parameters $\left(v_{\psi}, D_{\psi}\right)$ as well as TPL functional parameters $\left(\beta, t_{1}, t_{2}\right)$ as fitting parameters. The fitting parameters in DDMT model were mobile transport coefficients $\left(v_{m}, D_{m}\right)$, 
mobile porosity $\left(\eta_{m}\right)$, and mass transfer coefficient $(\xi)$. The latter two models contain more fitting parameters compared to ADE and offer more flexibility to obtain a better fit to the data, in particular when "anomalous" transport features characterize the solutes' breakthrough. The minimization of nonlinear least squares problems was performed with the MATLAB function Isqnonlin using a trust-region reflective algorithm [e.g., Coleman and $L i, 1996]$.

\subsection{Quantification of Transverse Dispersion}

In order to quantify the transverse displacement of the injected plumes in our quasi 2-D flow-through systems, we match the experimentally measured concentrations with the ADE model to obtain transverse dispersion coefficient, $D_{T}$. This can be done by fitting the 2-D analytical solution of equation (1) with the locally measured breakthrough curves at all individual outlet ports. Alternatively, following a similar approach to the one described in equation (3), we can further simplify the treatment by "decoupling" the transverse problem from the longitudinal one. The simplification is done by integrating the outlet concentrations over time at each vertical location. Thus, we consider only the plumes' displacement in the transverse direction. As done in equation (3), these timeintegrated concentrations are normalized by the time-integrated inflow boundary condition and we term this quantity as "boundary normalized integrated spatial profiles" or just "integrated spatial profiles" $\left(\left.\hat{C}(x, z)\right|_{B N} ^{S P}\right)$ :

$$
\left.\hat{C}(x, z)\right|_{B N} ^{S P}=\frac{\int_{0}^{\infty} C(x, z, t) d t}{\int_{0}^{\infty} g(z, t) d t}
$$

Along a specific cross section, the above time-integrated quantity of equation (9) produces the same outcome as the analytical solution for 2-D steady state transport (supporting information Figure S2) with a line source at the inlet [Domenico and Palciauskas, 1982]:

$$
C(x, z)=\frac{C_{0}}{2}\left\{\operatorname{erfc}\left(\frac{z-w / 2}{\sqrt{4 D_{T} X / v}}\right)-\operatorname{erfc}\left(\frac{z+w / 2}{\sqrt{4 D_{T} X / v}}\right)\right\}
$$

Therefore, we fit equation (10) to the time-integrated spatial profiles $\left(\left.\hat{C}(x, z)\right|_{B N} ^{S P}\right)$, calculated from our measured data, to characterize the transverse evolution $\left(D_{T}\right)$ of the injected tracers at the outlet of the domain.

\subsection{Evaluation of Plume Dilution}

As a metric of dilution, we use the flux-related dilution index. This quantity describes dilution as the "act of distributing a given solute mass flux over a larger water flux" and represents the effective volumetric water flux carrying the solute mass flux at a given longitudinal cross section [Rolle et al., 2009]. For transient transport in porous media, the flux-related dilution index can be written as [Rolle and Kitanidis, 2014]:

$$
E_{Q}(x, t)=\exp \left(-\int_{\Omega} p_{Q}(x, t) \ln p_{Q}(x, t) q_{x}(x, t) d \Omega\right)
$$

where $q_{x}=v \theta$ is the longitudinal component of specific discharge, $\Omega\left[\mathrm{L}^{2}\right]$ is the cross-sectional area perpendicular to the main flow, $\theta$ is the total porosity, and $p_{\mathrm{Q}}\left[\mathrm{T} / \mathrm{L}^{3}\right]$ is the flux-related probability density function at time $t$ :

$$
p_{Q}(x, t)=\frac{C(x, t)}{\int_{\Omega} C(x, t) q_{x}(x, t)}
$$

\subsection{Modeling Multicomponent lonic Dispersion}

The transport mechanism of charged solutes in a multi-ionic environment is conceptually different compared to the charge-neutral species due to the additional contribution of electrostatic interactions. Mathematically, transport processes of such charged species are commonly described by the Nernst-Planck formulation, by explicitly accounting for electrochemical potential gradients [e.g., Bard and Faulkner, 2001; Cussler, 2009]. For the multicomponent transport of dilute electrolyte solutions under the simplified condition of negligible ionic strength gradients, the total diffusive flux of ionic species is expressed as the 
additional contribution of a purely diffusive flux (Fick's law) and an electrochemical migration term [e.g., Lasaga, 1998; Boudreau et al., 2004; Appelo and Wersin, 2007]:

$$
J_{i}=-D_{i} \nabla C_{i}-D_{i} \frac{z_{i} F}{R T} C_{i} \nabla \Phi
$$

where $C_{i}$ is the concentration of a mobile charged species $i(i=1,2,3, \ldots, N), D_{i}$ is the "self-diffusion" coefficient (i.e., diffusion at its "liberated" state), $z_{\mathrm{i}}$ denotes the charge, $F$ is the Faraday's constant, $R$ is the ideal gas constant, $T$ is the temperature, and $\Phi$ is the electrostatic potential.

By considering the electroneutrality constraints of the solution: i.e., (i) condition of local charge-balance $\sum_{i=1}^{N} z_{i} C_{i}=0$ and/or (ii) condition of maintaining zero electrical current, $\sum_{i=1}^{N} z_{i} J_{i}=0$, the electrostatic potential gradient $(\nabla \Phi)$ can be expressed as:

$$
\nabla \Phi=\frac{-\sum_{i=1}^{N}\left(z_{i} D_{i} \nabla C_{i}\right)}{\sum_{i=1}^{N}\left(z_{i}^{2} F D_{i} C_{i}\right) / R T}
$$

As a result, the flux expression of equation (13) takes the form,

$$
J_{i}=-D_{i} \nabla C_{i}+\frac{z_{i} D_{i} C_{i}}{\sum_{j=1}^{N}\left(z_{j}^{2} D_{j} C_{j}\right)} \sum_{k=1}^{N}\left(z_{k} D_{k} \nabla C_{k}\right)
$$

This formulation enables accounting for both the movements due to the self-diffusion, as well as the concentration gradients of other dissolved charged species. Key steps regarding the detailed derivation of the above equations can be found in the works of Ben-Yaakov [1972], Lasaga [1979], Van Cappellen and Gaillard [1996]; Boudreau et al. [2004]; Appelo and Wersin [2007], Liu et al. [2011] among others. Under flow-through conditions, self-diffusion coefficients in equations (13)-(15) should be replaced by hydrodynamic dispersion coefficients since the transport is also influenced by the fluid flow [e.g., Rolle et al., 2013b; Muniruzzaman and Rolle, 2015]. Therefore, using the above flux expression, the governing multicomponent transport equation for ionic solutes in 2-D saturated porous media reads as:

$$
\frac{\partial C_{i}}{\partial t}=-v \frac{\partial C_{i}}{\partial x}+\frac{\partial}{\partial x}\left(\sum_{j=1}^{N} \mathbf{D}_{L}^{i j} \frac{\partial C_{i}}{\partial x}\right)+\frac{\partial}{\partial z}\left(\sum_{j=1}^{N} \mathbf{D}_{T}^{i j} \frac{\partial C_{i}}{\partial z}\right)
$$

in which $\mathbf{D}_{L}^{i j}$ and $\mathbf{D}_{T}^{i j}$ are the matrices of longitudinal and transverse cross-coupled dispersion terms [Muniruzzaman et al., 2014], respectively. These interdispersion coefficients are defined as:

$$
\begin{aligned}
& \mathbf{D}_{L}^{i j}=\delta_{i j} D_{L}^{i}-\frac{z_{i} z_{j} D_{L}^{i} D_{L}^{j} C_{i}}{\sum_{k=1}^{N}\left(z_{k}^{2} D_{L}^{k} C_{k}\right)} \\
& \mathbf{D}_{T}^{i j}=\delta_{i j} D_{T}^{i}-\frac{z_{i} z_{j} D_{T}^{i} D_{T}^{j} C_{i}}{\sum_{k=1}^{N}\left(z_{k}^{2} D_{T}^{k} C_{k}\right)}
\end{aligned}
$$

with $D_{L}^{i}$ and $D_{T}^{i}$ being the longitudinal and transverse "self-dispersion coefficient" (i.e., when a particular ion, $i$ is "liberated" from the other charged species in solution) and $\delta_{i j}$ being the Kronecker delta that is equal to 1 when $i=j$ and equal to 0 if $i \neq j$. The multicomponent ionic transport model is solved using a finite volume scheme (FVM) on streamline-oriented grids with the approach of Cirpka et al. [1999a, 1999b]. We use a discretization of $\Delta x=5 \mathrm{~mm}$ and $\Delta z=1 \mathrm{~mm}$ to simulate the outcomes obtained in our multicomponent ionic transport experiments. The simulations are performed using a pulse type boundary at the inlet and zero dispersive flux at the remaining boundaries. In order to linearize the nonlinearity induced from the coupled dispersive fluxes in the transport equations (equations (16) and (17)), we use a Picard iterative scheme to solve the system of equations. The concentration matrix is solved with the direct matrix solver UMFPACK [Davis and Duff, 1997] and the calculations are performed in MATLAB ${ }^{\circledR}$. Further information regarding the development of this multicomponent ionic modeling approach can be found in Muniruzzaman et al. [2014] and Muniruzzaman and Rolle [2016]. 


\section{Results and Discussion}

We performed experiments with two distinct sets of tracers: (i) multitracer experiments (with "noninteracting" tracers: fluorescein and chloride), and (ii) multicomponent ionic experiments (with electrostatically interacting $\mathrm{MgCl}_{2}$ solutions in different background solutions).

\subsection{Multitracer Experiments}

\subsubsection{Integrated Breakthrough Curves}

The experiments were performed at three planned nominal seepage velocities of $0.5,5$, and $25 \mathrm{~m} / \mathrm{d}$. The actual seepage velocities were determined by fitting the measured concentration breakthrough curves with the different models and the results, reported in Table 3, show an overall good agreement with the nominal values although some deviations were observed. In the following discussion, we refer to the experiments using the nominal values of seepage velocity. Specifically, we use the notation $v \approx 0.5,5$, and $25 \mathrm{~m} / \mathrm{d}$ to distinguish the three different cases. Chloride and fluorescein were used as tracers and measured at the outlet (Table 3). Chloride has significantly higher (approximately fourfold) diffusivity compared to that of fluorescein (Table 1). Figure 2 summarizes the integrated breakthrough curves (equation (3)) along with the flux-related dilution index (equation (11)) measured in the experiments at different seepage velocities at the outlet of the flow-through setup. The breakthrough of the tracers was observed with no retardation for chloride and with a slight retardation for fluorescein (linear retardation factor of $\sim 1.04$ ) due to weak sorptive interactions with the solid matrix. The breakthrough curves of the two tracers are reported as function of the pore volumes for direct comparison. Examining the temporal trend of the concentration profiles, integrated over the entire cross section, approximately bell-shaped curves for different velocities can be observed (Figures 2a-2c). However, the breakthrough curves for the two different tracers, chloride (black circles) and fluorescein (black crosses), show remarkably different spreading and peak concentrations at all velocities. The curves for chloride (solute with higher diffusivity, $D_{a q}=1.81 \times 10^{-9} \mathrm{~m}^{2} / \mathrm{s}$ ) exhibit higher peak concentrations and have less spread profiles than the ones of fluorescein (solute with lower diffusivity, $D_{a q}=0.45 \times 10^{-9} \mathrm{~m}^{2} / \mathrm{s}$ ).

The lines indicate the best fit modeled curves to the measured concentrations for three different transport models: ADE (red solid lines), CTRW (blue dash-dotted lines), and DDMT (green dashed lines) (Figures 2a2c). Table 3 lists the best fitted parameters obtained from the different models at different velocities. The fitted values of $D_{L}$, which is basically an indicator of the macroscopic spreading of the solute plumes in the longitudinal direction, also show consistent outcomes where the longitudinal dispersion of fluorescein is approximately double compared to the one of chloride in all experiments. Such separations in tracers' concentration profiles and spreading are quite remarkable especially for the cases with very high velocities $(v \approx$ 5 and $25 \mathrm{~m} / \mathrm{d}$ ), where transport is strongly advection-dominated.

Although, the compound-specific trends in these solute profiles are quite evident, the observed patterns show that the compound with higher diffusion coefficient (chloride) results in the less spread profile with

\begin{tabular}{|c|c|c|c|c|c|c|c|c|c|c|c|c|c|}
\hline \multirow[b]{3}{*}{ Model } & \multirow[b]{3}{*}{ Parameters } & \multicolumn{4}{|c|}{$v \approx 0.5 \mathrm{~m} / \mathrm{d}$} & \multicolumn{4}{|c|}{$v \approx 5 \mathrm{~m} / \mathrm{d}$} & \multicolumn{4}{|c|}{$v \approx 25 \mathrm{~m} / \mathrm{d}$} \\
\hline & & \multicolumn{2}{|c|}{ Chloride } & \multicolumn{2}{|c|}{ Flourescein } & \multicolumn{2}{|c|}{ Chloride } & \multicolumn{2}{|c|}{ Flourescein } & \multicolumn{2}{|c|}{ Chloride } & \multicolumn{2}{|c|}{ Flourescein } \\
\hline & & $\begin{array}{l}\text { Best Fit } \\
(p)\end{array}$ & $\begin{array}{c}\text { Std. Dev. } \\
\left(\sigma_{p}\right)\end{array}$ & $\begin{array}{l}\text { Best Fit } \\
\quad(p)\end{array}$ & $\begin{array}{l}\text { Std. Dev. } \\
\left(\sigma_{p}\right)\end{array}$ & $\begin{array}{c}\text { Best Fit } \\
(p)\end{array}$ & $\begin{array}{l}\text { Std. Dev. } \\
\left(\sigma_{p}\right)\end{array}$ & $\begin{array}{l}\text { Best Fit } \\
\quad(p)\end{array}$ & $\begin{array}{l}\text { Std. Dev. } \\
\left(\sigma_{\mathrm{p}}\right)\end{array}$ & $\begin{array}{l}\text { Best Fit } \\
\quad(p)\end{array}$ & $\begin{array}{l}\text { Std. Dev. } \\
\left(\sigma_{\mathrm{p}}\right)\end{array}$ & $\begin{array}{l}\text { Best Fit } \\
\quad(p)\end{array}$ & $\begin{array}{l}\text { Std. Dev. } \\
\left(\sigma_{\mathrm{p}}\right)\end{array}$ \\
\hline \multirow[t]{3}{*}{ ADE } & $v(\mathrm{~m} / \mathrm{d})$ & 0.62 & $3.80 \times 10^{-4}$ & 0.57 & $4.66 \times 10^{-4}$ & 4.83 & $2.77 \times 10^{-3}$ & 4.60 & $2.32 \times 10^{-3}$ & 21.78 & $2.62 \times 10^{-2}$ & 20.57 & $1.76 \times 10^{-2}$ \\
\hline & $D_{\mathrm{L}}\left(\mathrm{m}^{2} / \mathrm{s}\right)$ & $2.64 \times 10^{-9}$ & $1.23 \times 10^{-10}$ & $4.04 \times 10^{-9}$ & $1.69 \times 10^{-9}$ & $3.21 \times 10^{-8}$ & $8.92 \times 10^{-10}$ & $6.86 \times 10^{-8}$ & $9.54 \times 10^{-10}$ & $1.30 \times 10^{-7}$ & $8.18 \times 10^{-9}$ & $3.44 \times 10^{-7}$ & $7.88 \times 10^{-9}$ \\
\hline & $D_{\mathrm{T}}\left(\mathrm{m}^{2} / \mathrm{s}\right)$ & $2.16 \times 10^{-9}$ & $3.41 \times 10^{-10}$ & $9.19 \times 10^{-10}$ & $3.66 \times 10^{-11}$ & $6.67 \times 10^{-9}$ & $2.97 \times 10^{-10}$ & $3.45 \times 10^{-9}$ & $1.50 \times 10^{-10}$ & $1.74 \times 10^{-8}$ & $8.27 \times 10^{-10}$ & $1.10 \times 10^{-8}$ & $6.44 \times 10^{-10}$ \\
\hline \multirow[t]{5}{*}{ CTRW } & $v_{\psi}(\mathrm{m} / \mathrm{d})$ & 0.45 & $6.78 \times 10^{-9}$ & 0.73 & $4.46 \times 10^{-6}$ & 4.78 & $3.52 \times 10^{-5}$ & 4.79 & $2.24 \times 10^{-4}$ & 38.88 & $5.16 \mathrm{E}-04$ & 26.64 & $1.49 \times 10^{-3}$ \\
\hline & $D_{\psi}\left(\mathrm{m}^{2} / \mathrm{s}\right)$ & $2.76 \times 10^{-10}$ & $1.23 \times 10^{-13}$ & $2.57 \times 10^{-9}$ & $5.22 \times 10^{-11}$ & $1.60 \times 10^{-8}$ & $1.91 \times 10^{-10}$ & $4.37 \times 10^{-8}$ & $3.43 \times 10^{-10}$ & $1.83 \times 10^{-8}$ & $1.01 \times 10^{-9}$ & $1.69 \times 10^{-7}$ & $2.14 \times 10^{-9}$ \\
\hline & $\beta$ & 2.364 & $4.40 \times 10^{-10}$ & 1.781 & $2.08 \times 10^{-8}$ & 2.006 & $2.15 \times 10^{-9}$ & 1.957 & $4.29 \times 10^{-9}$ & 1.549 & $5.18 \times 10^{-7}$ & 1.768 & $7.31 \times 10^{-8}$ \\
\hline & $t_{1}(\min )$ & $4.38 \times 10^{-1}$ & $7.34 \times 10^{-9}$ & $7.90 \times 10^{-2}$ & $2.96 \times 10^{-9}$ & $2.20 \times 10^{-2}$ & $3.70 \times 10^{-10}$ & $2.43 \times 10^{-2}$ & $6.20 \times 10^{-10}$ & $6.92 \times 10^{-4}$ & $4.8 \times 10^{-9}$ & $6.28 \times 10^{-3}$ & $5.88 \times 10^{-9}$ \\
\hline & $t_{2}(\min )$ & $9.16 \times 10^{7}$ & 0.13 & $7.53 \times 10^{9}$ & 243.12 & $1.81 \times 10^{8}$ & 1.94 & $1.41 \times 10^{8}$ & 25.15 & $1.41 \times 10^{8}$ & 292.98 & $1.41 \times 10^{8}$ & 14.467 \\
\hline \multirow[t]{4}{*}{ DDMT } & $v_{\mathrm{m}}(\mathrm{m} / \mathrm{d})$ & 0.62 & 0.0005 & 0.58 & 0.0005 & 4.84 & 0.0039 & 4.60 & 0.0730 & 21.95 & 0.02226 & 20.61 & 0.1755 \\
\hline & $D_{\mathrm{m}}\left(\mathrm{m}^{2} / \mathrm{s}\right)$ & $2.23 \times 10^{-9}$ & $4.10 \times 10^{-10}$ & $2.74 \times 10^{-9}$ & $4.34 \times 10^{-10}$ & $3.03 \times 10^{-8}$ & $9.21 \times 10^{-10}$ & $6.77 \times 10^{-8}$ & $1.36 \times 10^{-9}$ & $8.08 \times 10^{-8}$ & $1.18 \times 10^{-8}$ & $3.21 \times 10^{-7}$ & $1.08 \times 10^{-8}$ \\
\hline & $\eta_{\mathrm{m}}$ & 0.4070 & 0.0020 & 0.4038 & 0.0011 & 0.4056 & 0.0002 & 0.4034 & 0.0063 & 0.4015 & 0.0006 & 0.4018 & 0.0031 \\
\hline & $\xi(1 / s)$ & $2.46 \times 10^{-6}$ & $3.61 \times 10^{-6}$ & $1.16 \times 10^{-6}$ & $2.97 \times 10^{-7}$ & $1.25 \times 10^{-6}$ & $1.64 \times 10^{-8}$ & $4.77 \times 10^{-7}$ & $9.47 \times 10^{-8}$ & $4.37 \times 10^{-5}$ & $6.24 \times 10^{-6}$ & $8.20 \times 10^{-6}$ & $4.76 \times 10^{-7}$ \\
\hline
\end{tabular}


significantly higher peak concentration compared to the compound with lower diffusivity (fluorescein). This behavior may appear counterintuitive and, based on the exclusive analysis of these integrated breakthrough curves, one may come to the erroneous conclusion that the more spread and less peaked fluorescein profiles correspond to the more diluted plumes. A similar behavior was observed in the pore-scale modeling study of Rolle and Kitanidis [2014], who argued that this behavior is due to the fact that, in advection-dominated regimes, the transport departs from being close to physical equilibrium and spreading ceases to be a good proxy for plume dilution and mixing. This was the case in all experimental setups, in fact, even the experiment with the lowest seepage velocity $(v \approx 0.5 \mathrm{~m} / \mathrm{d})$, which lies in the upper limit of typical natural groundwater flow, is characterized by a grain Péclet number greater than 1 for both chloride and fluorescein (Table 2). A metric such as the flux-related dilution index is helpful to distinguish spreading and mixing from the outlet measurements. We computed the flux-related dilution index of the tracer plumes at the outlet at different time points by using the concentrations and volumetric fluxes measured at each individual outlet port (equation (11)). The results show a different pattern compared to the concentration breakthrough curves and suggest that the chloride (tracer with higher $D_{a q}$ ) plume is remarkably more diluted compared to fluorescein plume at all velocities (Figures $2 \mathrm{~d}-2 \mathrm{f}$ ). Therefore, despite the more spread integrated breakthrough curves, the water fluxes carrying the fluorescein plumes are, in fact, $40 \%, \sim 33 \%$, and $\sim 20 \%$ smaller compared to the ones transporting the chloride plume at the flow velocity of $0.5,5$, and $25 \mathrm{~m} / \mathrm{d}$, respectively. The fact that the chloride plumes are more diluted than those of fluorescein directly stems from the higher diffusivity of chloride. Consequently, even though the different tracer pulses were simultaneously injected in the macroscopically homogeneous domain, the tracer compounds evolve differently through the pore-channels because of the different diffusivity and the different extent of incomplete mixing in the pores at these high flow velocities. The macroscopic result of these small-scale processes is that the solute with higher diffusivity is distributed over larger volumes and water fluxes. Notice that, although rather intuitive, these results cannot be explained by classical dispersion theory using the common linear parameterization, $D=D_{P}+\alpha v$ [Scheidegger, 1961]. According to this parameterization, diffusion only acts through the velocity-independent pore diffusion term $\left(D_{P}\right)$ and, thus, should only play a minor or negligible role in advection and strongly advection-dominated regimes. Therefore, in contrast to what was observed in the experiments, the same distribution of different solutes at high flow velocity would be expected, due to the fact that in these conditions the mechanical dispersion term dominates. The latter term is described as the product of the seepage velocity and a dispersivity coefficient $(\alpha)$, typically assumed to be a property of the porous medium.

The trends of $E_{Q}(x, t)$ profiles for different solutes at the outlet are also quite interesting (Figures $2 \mathrm{~d}-2 \mathrm{f}$ ). Instead of a monotonically increasing pattern as expected from a Gaussian plume, the dilution profiles have a tendency to either level off or decrease after the mean arrival time. Rolle and Kitanidis [2014] observed a similar behavior in pore-scale simulations and pointed out that this effect is determined by two competing factors: the tendency of increasing dilution with travel time and/or travel distance, and the incompletemixing at the pore-scale resulting in mass transfer limitations occurring at these rather high flow velocities leading to an effect of "undiluteness" for the different solute plumes. The absolute values of flux-related dilution indices $\left(E_{Q}\right)$ also increase with increasing average seepage velocity (Figures $\left.2 d-2 f\right)$. The incomplete mixing and "undiluteness" effect is also visible in the concentration breakthrough curves, especially at high flow velocities $(v \approx 5$ and $25 \mathrm{~m} / \mathrm{d}$ ), with the presence of a tailing at late times (Figures $2 \mathrm{~b}-2 \mathrm{~d}$ ). Such effects are indicative of "non-Fickian" or "anomalous" transport behavior. As an example, this behavior is illustrated in Figure 3 by plotting the concentration profiles of the experiment at $v \approx 25 \mathrm{~m} / \mathrm{d}$ in log-scale in order to specifically focus on the long-term tailings. In the logarithmic plots, it is evident that both tracer compounds show considerable extent of tailing where the ADE model (red solid lines) shows deviation from the data (Figures $3 a$ and 3b). On the other hand, the CTRW (blue dashed-dotted lines) and the DDMT (green-dashed lines) model are able to effectively capture the plume tails. The residuals between the data points and the best fitted modeled values, weighted by the measured values, also confirm consistent outcomes where both CTRW (blue crosses) and DDMT (green squares) model show smaller magnitudes of the weighted residuals at late times (Figures $3 c$ and $3 d$ ). This feature evidently indicates the better performance of these two models over the ADE model (red circles) in reproducing the late-time behaviors (PV $>1.1$ ) for both tracer plumes. The characteristics of anomalous nature of the transport are also appreciable from the fitted parameters obtained from the CTRW and DDMT models (Table 3). 

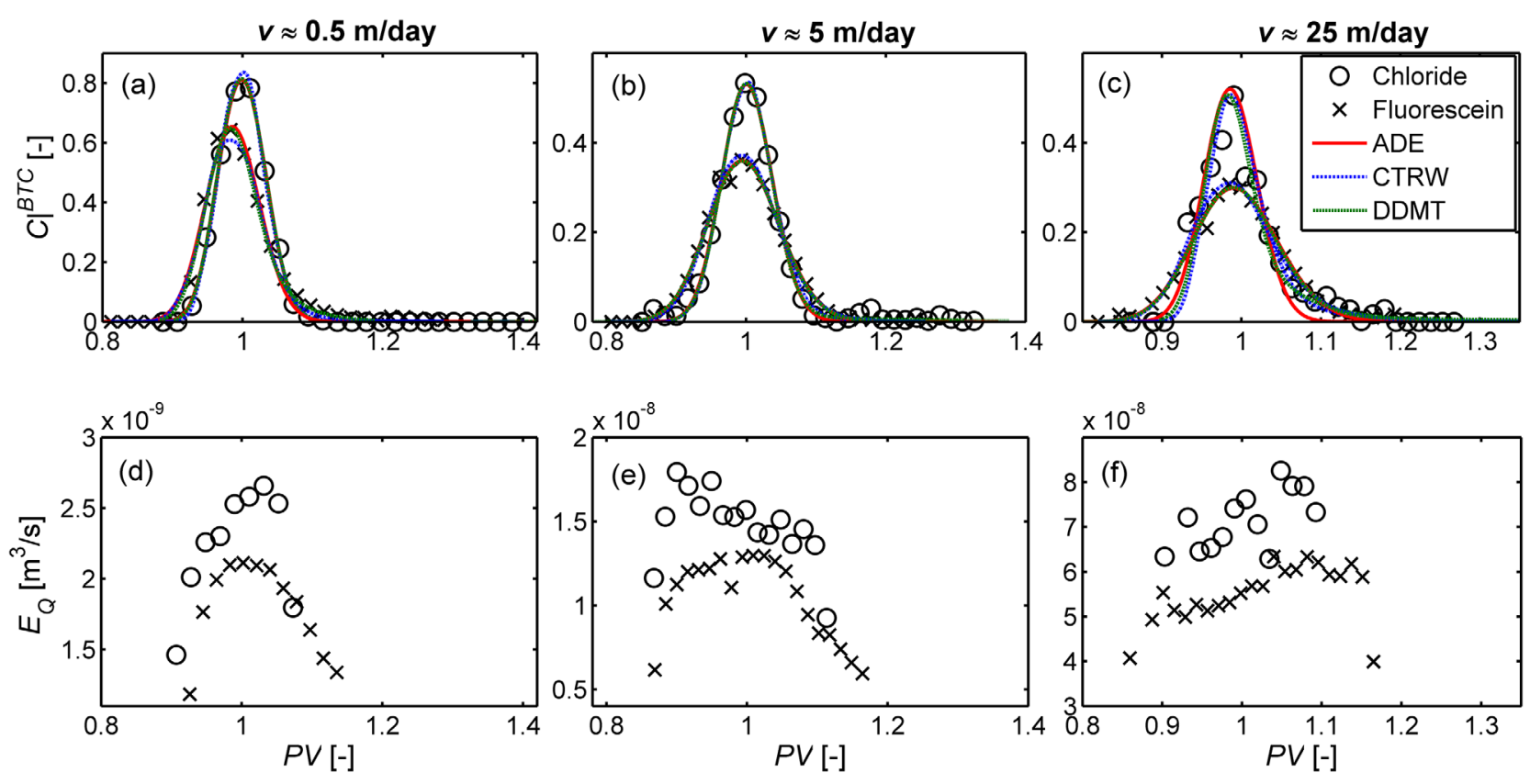

Figure 2. (a-c) Breakthrough curves of the flux-weighted integrated concentrations normalized by the flux-weighted inflow boundary conditions, and (d-f) flux-related dilution index at the outlet cross-section for the seepage velocities of (a and d) $0.5 \mathrm{~m} / \mathrm{d}$, (b and e) $5 \mathrm{~m} / \mathrm{d}$, and (c and f) $25 \mathrm{~m} / \mathrm{d}$.

Figure 4 shows selected parameters for each model that were obtained from the fitting with experimental data. Figure $4 a$ summarizes the longitudinal dispersion coefficients $\left(D_{L}\right)$ estimated with the ADE model. The results show distinct values for fluorescein and chloride at all three seepage velocities. The experimentally determined $D_{L}$ values, represented in a normalized plot $\left(D_{L} / D_{a q}\right.$ versus $\left.P e\right)$, appear to follow a linear or weakly nonlinear trend that appears to be captured by previously proposed correlations for longitudinal dispersion in porous media [e.g., Bijeljic et al., 2004; Guedes de Carvalho and Delgado, 2005] (Figure 4b). In CTRW, $\beta$ is the parameter that determines the extent of anomalous transport with $0<\beta<2$ indicating the existence of non-Fickian behavior. For $\beta>2$, the transport reduces to classical Fickian form. For $v \approx 0.5$ and $5 \mathrm{~m} / \mathrm{d}$, the best-fit $\beta$ values for chloride are 2.364 and 2.006, respectively; whereas for fluorescein the obtained values of $\beta$ are 1.781 and 1.957 , respectively (Figure $4 c$ and Table 3 ). These values suggest that, while the chloride transport stays in the Fickian regime, the transport of fluorescein becomes "weakly" anomalous even in this homogeneously packed quasi 2-D flow-through setup. These values and their interpretation appear to be reasonable also with respect to the fundamental physical processes in the pore channels and with the compound-specific behavior resulting in fluorescein (lower diffusivity) being relatively more influenced by the incomplete-mixing in the pores than chloride (higher diffusivity). Conversely, at the highest velocity tested $(v \approx 25 \mathrm{~m} / \mathrm{d}$ ), a $\beta<2$ is obtained for both tracer compounds demonstrating that at such high advective velocity both tracers show anomalous behavior.

The parameters obtained by fitting the DDMT model can also be used to explain the observed behavior of the different tracer plumes (Table 3). For the first two experiments ( $v \approx 0.5$ and $5 \mathrm{~m} /$ day), the fitted mobile fraction $\left(\eta_{m}\right)$ of total porosity $(\theta=0.41)$ for chloride is slightly higher compared to the values obtained for fluorescein. On the other hand, practically identical results were obtained for the experiments at the highest Péclet number $(v \approx 25 \mathrm{~m} / \mathrm{d})$. As observed for the ADE and the CTRW models, also for the DDMT nonunique and compoundspecific fitting parameters were obtained at the different flow velocities. In particular, the higher mass-transfer coefficients obtained for chloride can be related to the higher diffusivity of this species (Figure 4d).

4.1.2. Port-Resolved Breakthrough Curves

Figure 5 depicts the maps of the concentration measurements performed at different locations along the outlet of our 2-D experimental domain at different times. The measurements are shown as concentrations normalized by the corresponding inlet concentrations for each tracer. The top two rows of plots denote the measured data points plotted with vertical locations $(z)$ and data collection time (PV) for different velocities 
(a) Chloride BTC

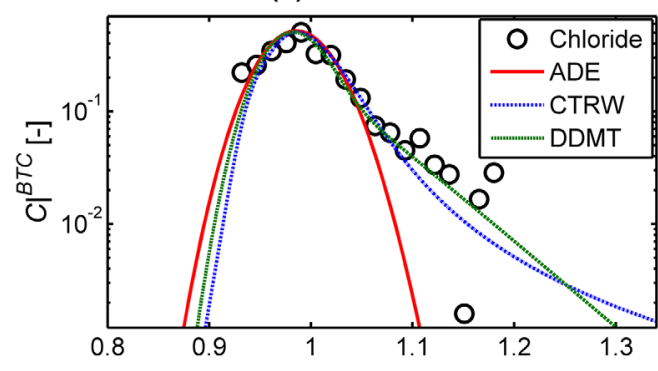

(c) Chloride Residuals

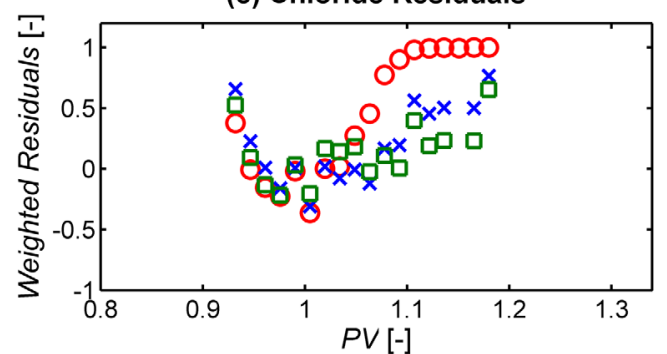

(b) Fluorescein BTC

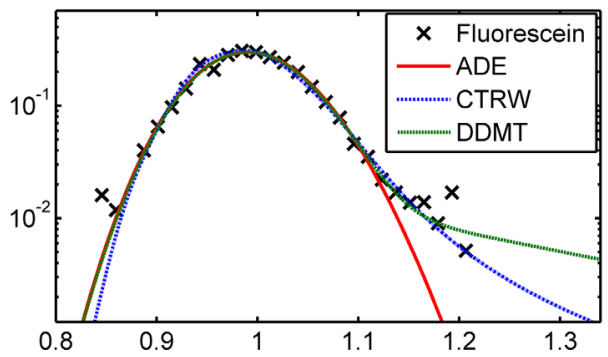

(d) Fluorescein Residuals

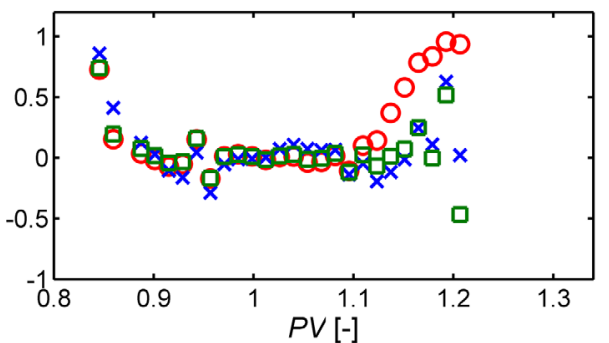

Figure 3. ( $\mathrm{a}$ and $\mathrm{b}$ ) Breakthrough curves of the flux-weighted integrated concentrations normalized by the flux-weighted inflow boundary conditions in logarithmic scale and (c and d) the weighted residuals at the seepage velocity of $25 \mathrm{~m} / \mathrm{d}$.

(Figures 5a-5f). Each grid block in these plots indicates a measurement point across the time and space; whereas the respective concentration value is shown with the color. The lower two rows of plots represent the cubic interpolation of the measured concentration values (Figures $5 \mathrm{~g}-5 \mathrm{l}$ ). The white dots delineate the contours of the interpolated normalized concentrations, whereas the solid lines represent the corresponding ADE predicted contours shown at levels 0.02 and 0.1 . This representation helps visualizing the overall shape of the tracer plumes arriving at the outlet cross section. In fact, assuming a macroscopically homogeneous domain and a constant advective velocity, the time axis can be translated into space with $x=v t$. So, these concentration distributions can be viewed as analogous to a snapshot of the spatial distribution of the tracer plume at the mean breakthrough time.

As pointed out earlier from the analysis of the integrated temporal profiles, there are significant differences in the shape and spreading between the two tracer compounds. At lower Péclet number $(v \approx 0.5 \mathrm{~m} / \mathrm{d})$, the shape of a particular compound's plume tend to be less elongated (left column; Figure 4); whereas with the increasing seepage velocity $(v \approx 5$ and $25 \mathrm{~m} / \mathrm{d})$, the plume becomes more stretched along the longitudinal/ time axis (middle and right columns in Figure 5). This is expected since at high flow velocity, the small characteristic advective time does not allow enough time for diffusion to act. This limits the macroscopic transverse displacement of the tracer plume, and at the pore scale, it results in incomplete mixing in the pore channels in highly advection-dominated systems.

It is interesting to note that fluorescein (Figures $5 d-5 f, 5 j-5 l)$ has a much longer and stretched plume compared to chloride (Figures $5 a-5 c, 5 g-5 i)$ at all flow velocities. This implies that following the simultaneous injection (with same initial size and shape), the tracer compounds undergo significantly different extents of spreading and mixing. These differences are attributed to their diffusive mobilites because both tracers are simultaneously transported under identical hydraulic and transport conditions and through the same pore network. Such behavior is remarkable and confirms that the compound-specific effect does not vanish even at high pore-water velocities and can lead to significant differences in multispecies transport.

Figure 6 summarizes the breakthrough curves measured at different vertical locations $(z)$ for the specific case of $v \approx 5 \mathrm{~m} / \mathrm{d}$. The profiles measured at the central outlet ports of the vertical cross-section correspond to the core of the plumes and look similar to the integrated profiles of Figure 2 (Figures $6 c-6 f$ ). At the top and bottom locations (i.e., plume fringe area), the differences between the peak concentrations of the two tracer compounds tend to increase (Figures $6 a, 6 b, 6 g-6 i)$. Such discrepancies arise from the differences in diffusion coefficients; where the higher $D_{a q}$ of chloride leads to further transverse displacement. Hence, 

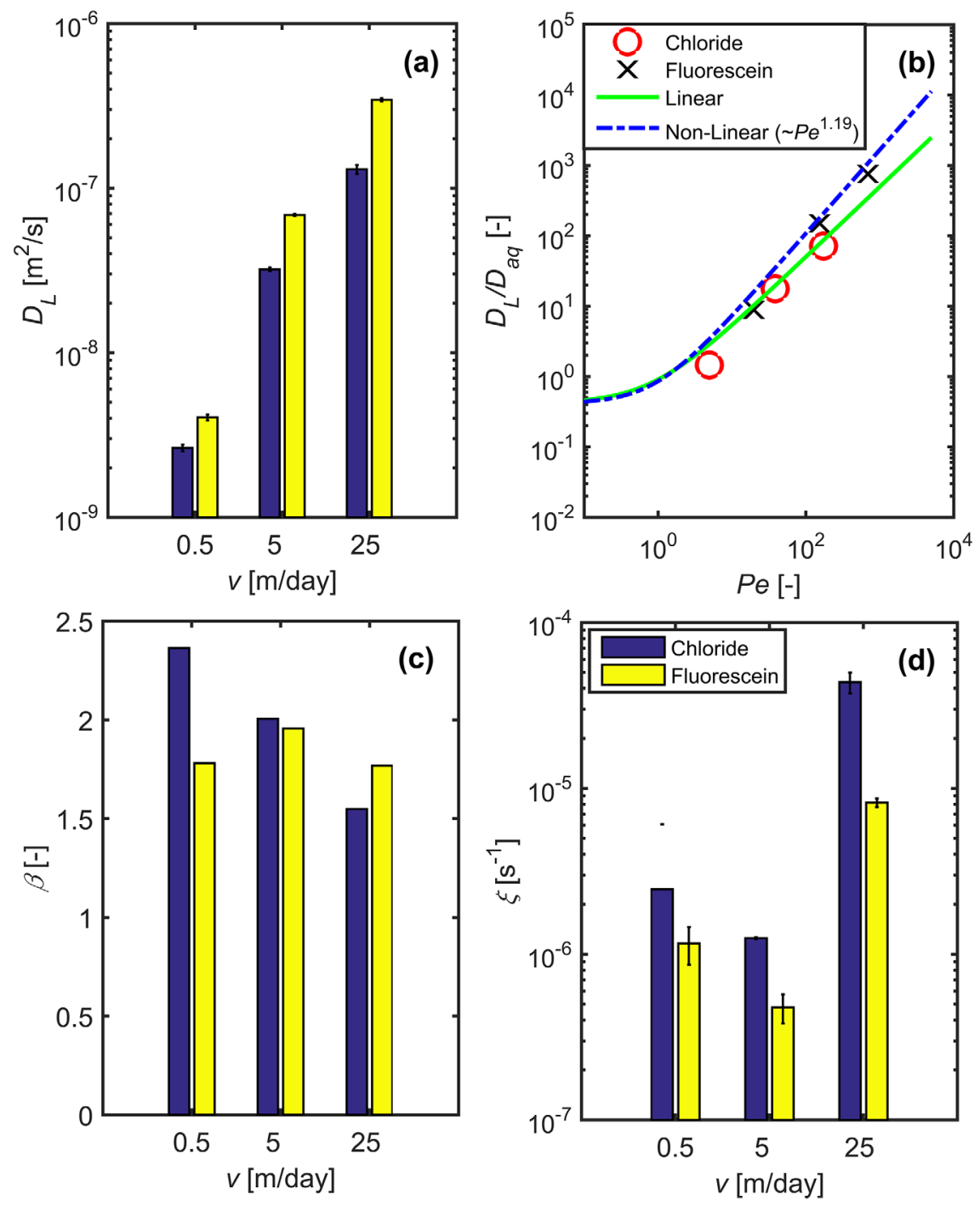

Figure 4. Selected fitted parameters obtained from the integrated breakthrough curves using different models: (a and b) $D_{L}$ for $A D E$, (c) $\beta$ for CTRW, and (d) $\xi$ for DDMT model.

considerably higher peak concentrations of chloride are observed in the upper and lower plume fringe compared to the ones of fluorescein (Figures $6 \mathrm{a}$ and $6 \mathrm{i}$ ). The measured data were fitted with the different transport models (ADE, CTRW, and DDMT) for all locally measured profiles. In each port, the fitting was performed as 1-D transport problem (equation (2)) by considering the transport occurring along a streamtube from the point of injection to the point of observation (i.e., as if we consider each streamtube as an independent 1-D column).

It is important to mention that, the fitted longitudinal dispersion $\left(D_{L}\right)$ values determined in different vertical locations show variability for both tracers (listed in supporting information Table S4). While the central ports show values similar to the one obtained from the integrated profiles, $D_{L}$ has a decreasing trend especially from the core to the fringe of the plume. Also notice that at the outer fringe the quality of the fits decreases due to the considerably lower values and more scattered patterns of measured concentrations. Fluorescein plumes typically show a higher dispersion coefficient, indicating more spreading along the streamtube (supporting information Table S4).

The calculated values of average seepage velocities $(v)$ in each port are also consistent with the measured flow rates in the respective port. The degrees of anomalous behavior of chloride and fluorescein, 


\section{QAGU Water Resources Research}

(a) $v \approx 0.5 \mathrm{~m} /$ day: Chloride

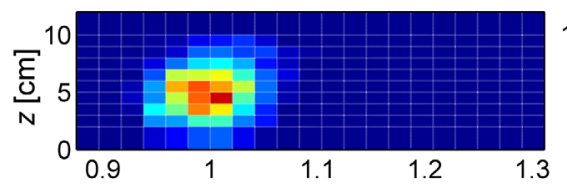

(d) $v \approx 0.5 \mathrm{~m} /$ day: Fluorescein

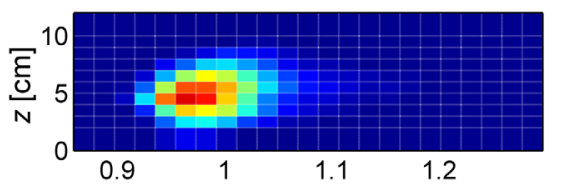

(g) $v \approx 0.5 \mathrm{~m} /$ day: Chloride

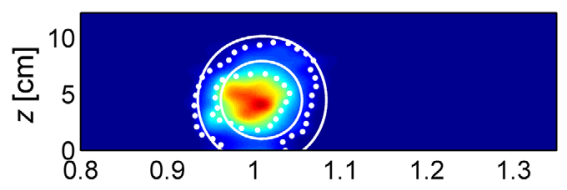

(j) $v \approx 0.5 \mathrm{~m} /$ day: Fluorescein

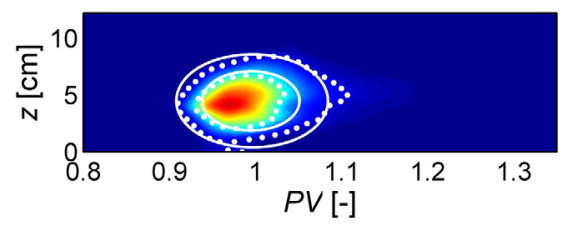

(b) $v \approx 5 \mathrm{~m} /$ day: Chloride

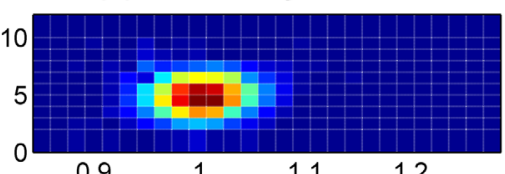

1.2

(e) $v \approx 5 \mathrm{~m} /$ day: Fluorescein

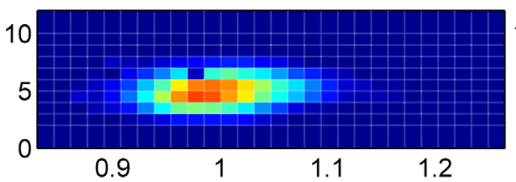

(h) $v \approx 5 \mathrm{~m} /$ day: Chloride

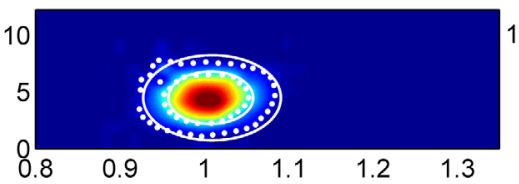

(k) $v \approx 5$ m/day: Fluorescein

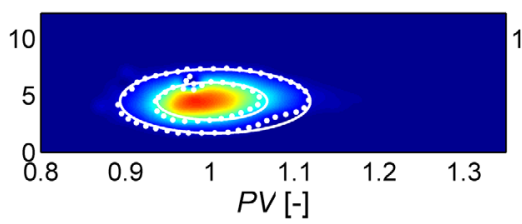

(c) $v \approx \mathbf{2 5} \mathrm{m} /$ day: Chloride $C / C_{\text {in }}[-]$

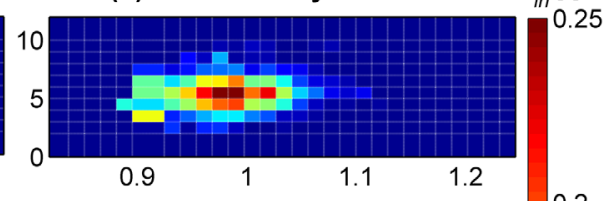

(f) $v \approx 25 \mathrm{~m} /$ day: Fluorescein

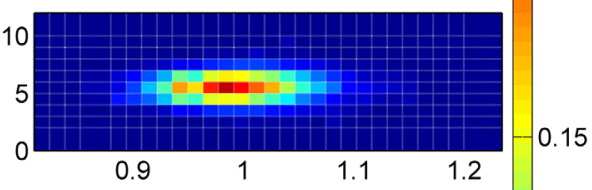

(i) $v \approx 25 \mathrm{~m} /$ day: Chloride

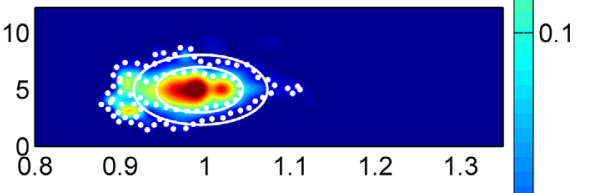

(I) $v \approx 25 \mathrm{~m} /$ day: Fluorescein

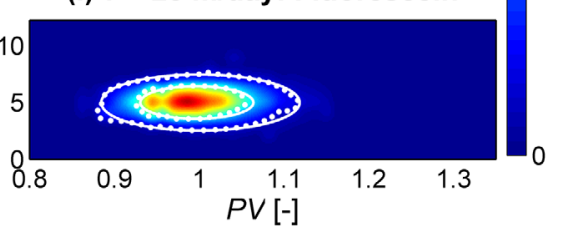

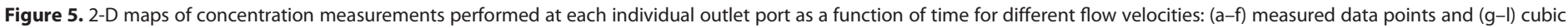

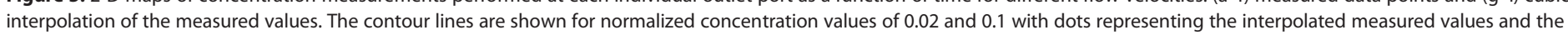
solid lines being the ADE-predicted values.

interpreted based on the outcomes of the CTRW fits, are in a similar range as obtained from their integrated profiles. For chloride, $\beta=2.004-2.015$ was found for different locations of the plume; whereas the fitted $\beta$ for fluorescein stayed slightly below 2 (1.849 - 1.989) indicating the existence of "weak" non-Fickian behavior. The DDMT model fitting also suggests similar outcomes, as obtained from the CTRW model.

4.1.3. Transverse Spreading and Dispersion

We analyze the transverse displacement of the tracer plumes by integrating the concentration measurements along the time axis (equation (9)). This temporal integration, basically, determines the fraction of total injected tracer mass (zeroth temporal moments) recovered at each outlet port. In particular, with this approach, we eliminate the longitudinal plume evolution/spreading by disregarding any concentration gradient along each advective travel path of our 2-D domain. Consequently, the transport of the 2-D tracer pulse reduces to a more simplified form, which describes only the lateral concentration distribution in different longitudinal cross-sections. As explained in section 3.2, these time-integrated vertical concentration profiles normalized by the temporal integral of the inflow boundary condition $\left(\left.\hat{C}(x, z)\right|_{B N} ^{S P}\right)$ agree very well with the 2-D steady state analytical solution of equation (10). We quantify the transverse dispersion coefficient $\left(D_{T}\right)$ of different tracers by fitting equation (10) to the measurements by using the seepage velocities obtained from the integrated breakthrough profiles. For simplicity, we only fit the ADE model here to obtain the extent of transverse displacement.

Figure 7 represents the time-integrated spatial profiles for different cases at the end of our experimental domain. It is interesting to notice that the spreading and peak concentrations of the two tracers show a completely opposite behavior compared to the observations for the integrated breakthrough curves (Figure 2). In fact, in the lateral direction, the compound-specific behavior is more intuitive to interpret: chloride, the tracer with higher $D_{a q}$, has more spread profiles with lower peak concentrations compared to the ones of fluorescein (lower $\left.D_{a q}\right)$. Even in the case of strongly advection-dominated transport $(v \approx 25 \mathrm{~m} /$ day, 


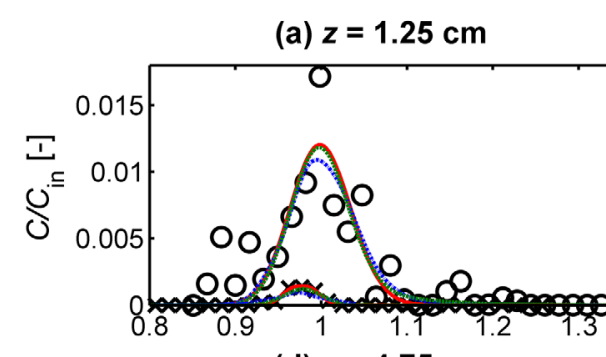

(d) $z=4.75 \mathrm{~cm}$

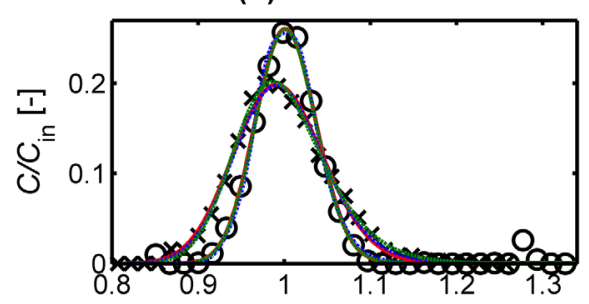

(g) $z=7.75 \mathrm{~cm}$

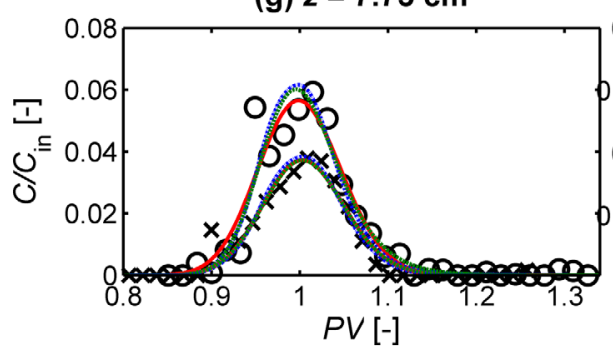

(b) $z=2.75 \mathrm{~cm}$

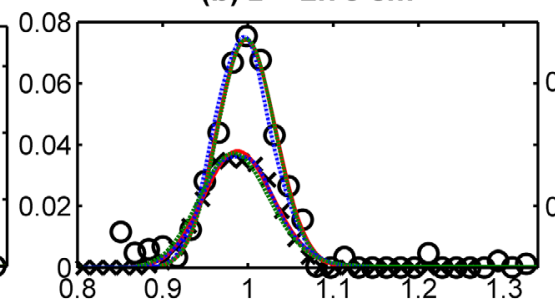

(e) $z=5.75 \mathrm{~cm}$

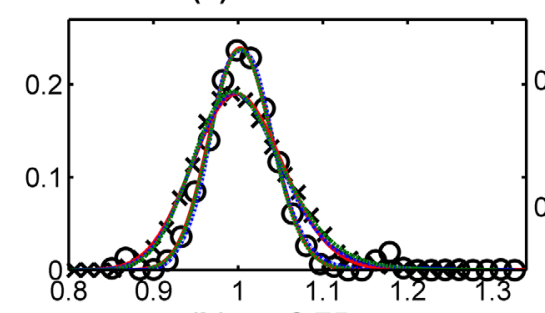

(h) $z=8.75 \mathrm{~cm}$

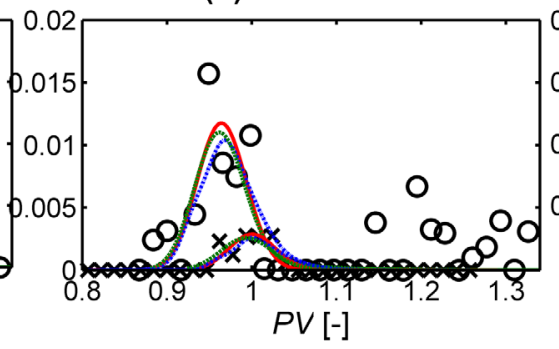

(c) $z=3.75 \mathrm{~cm}$

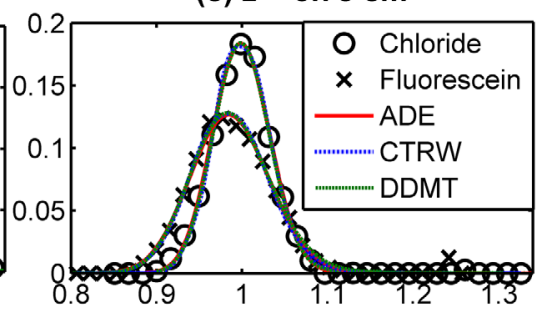

(f) $z=6.75 \mathrm{~cm}$

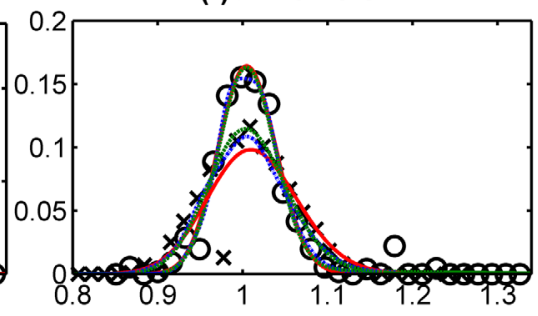

(i) $z=9.75 \mathrm{~cm}$

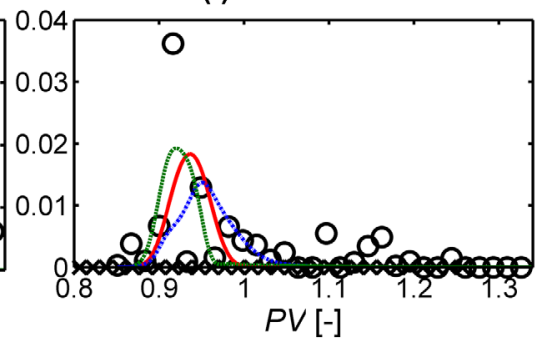

Figure 6. Breakthrough curves measured at each individual port for the seepage velocity of $5 \mathrm{~m} / \mathrm{d}$.

Figure 7c), the compound-specific migration is significant and a considerable separation between the two tracer profiles exists. Therefore, as pointed out from the analysis of the flux-related dilution index profiles for the integrated breakthrough curves (Figures $2 d-2 f$ ) and in the 2-D mapping of the plumes from the outlet measurements (Figure 5), the more diluted chloride plume shows more significant lateral displacement at all flow velocities.

The fitted transverse dispersion coefficients $\left(D_{T}\right)$ listed in Table 3 also show that the less mobile fluorescein has always a smaller value compared to chloride for all flow velocities. These $D_{T}$ values are in very good agreement with the predictions from a non-linear compound-specific transverse dispersion parameterization (Figure 8). Such parameterization was inspired by an earlier statistical model of Bear and Bachmat [1967] and was developed based on steady state flow-through experiments in the works of Chiogna et al. [2010] and Rolle et al. [2012]. The parameterization reads as:

$$
D_{T}=D_{P}+D_{a q}\left(\frac{P e^{2}}{P e+2+4 \delta^{2}}\right)^{B}
$$

where $D_{P}\left[\mathrm{~L}^{2} / \mathrm{T}\right]$ is the pore diffusion coefficient; $P$ e denotes the grain Péclet number, defined as $P e=v d / D_{a q}$ $(d[\mathrm{~L}]$ is the average grain size diameter); $\delta$ is the ratio between the length of a pore channel to its hydraulic radius; and $B$ is an empirical exponent accounting for incomplete mixing in pore channels. Notice that, in order to avoid confusions with $\beta$ in CTRW interpretations, we use a capital beta (B) in equation (18). The values $\delta$ and $\mathrm{B}$ were characterized by conducting a series of multitracer laboratory and pore-scale experiments across a wide range of flow velocity and in porous media with different grain sizes [Rolle et al., 2012; Hochstetler et al., 2013; Ye et al., 2015a, 2015b]. In our calculations, we use $\delta=6.2$ and B $=0.5$, which are representative for the porous medium used in this study. 


\section{QAGU Water Resources Research}
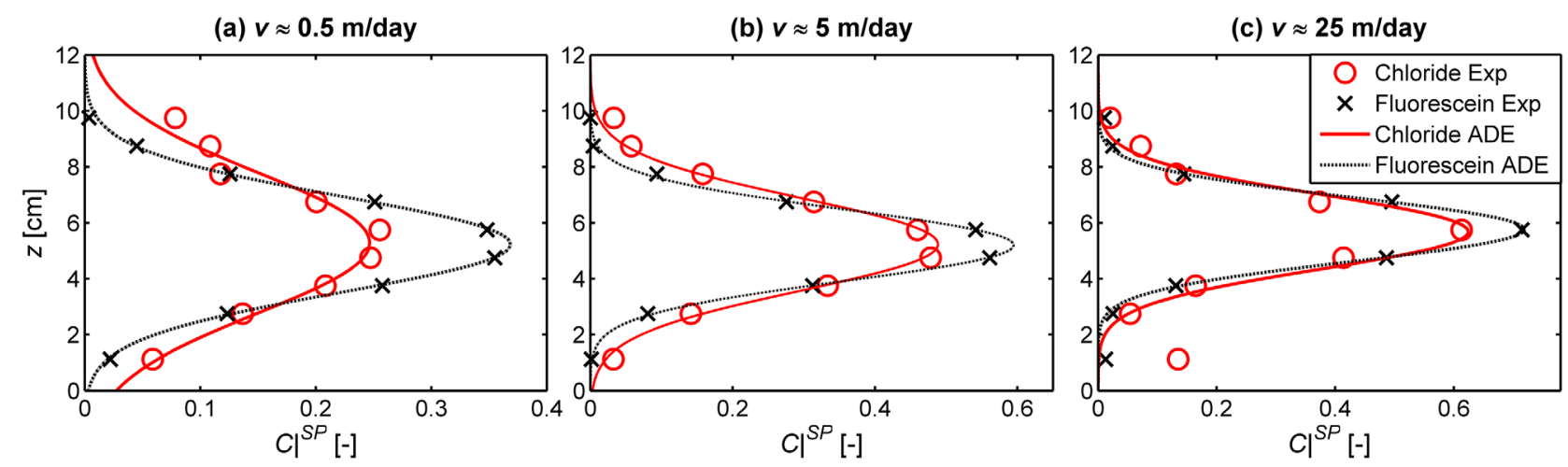

Figure 7. Time-integrated transverse concentration profiles, normalized by the temporal integral of the inflow boundary condition, for the seepage velocities of (a) 0.5 , (b) 5 , and (c) 25 (c) $\mathrm{m} / \mathrm{d}$.

Figure 8a directly compares the experimentally determined $D_{T}$ values (markers) with the computed ones according to equation (18) (continuous line) as a function of $P e$; whereas Figure $8 \mathrm{~b}$ illustrates the pattern of $D_{T}$ as a function of the seepage velocity, $v$. It is remarkable to notice that the compound-specific effects on transverse dispersion are also relevant at high advective velocities, including at $v \approx 25 \mathrm{~m} / \mathrm{d}$ (Figure $8 \mathrm{~b}$ ). In fact, the separation between the two tracer dispersion coefficients has an increasing trend with increasing seepage velocities. Equation (18) captures this behavior by considering an explicit dependence of the mechanical dispersion term on the aqueous diffusion coefficients. Notice that, at the upper limit of our experimental seepage velocities $(v \approx 25 \mathrm{~m} / \mathrm{d})$, the mechanical dispersion term is almost two orders of magnitudes higher relative to the pore diffusion term. Therefore, the transient multitracer experiments performed in this study confirm the importance of considering the dependence of mechanical dispersion on both flow-velocity and species diffusivity, which was previously experimentally investigated only under steady state conditions and considering continuous injection [Chiogna et al., 2010; Rolle et al., 2012].

\subsection{Multicomponent lonic Experiments}

As summarized in Table 2, experiments were also performed to identify the impact of Coulombic interactions during transient multicomponent ionic transport. Focusing on different settings of ionic tracers, we consider two distinct experiments, in which the first one includes the injection of a pulse of a 1:2 electrolyte $\left(\mathrm{MgCl}_{2} ; 0.8 \mathrm{mM}\right)$ solution in pure water. The second experiment was performed by injecting the same electrolyte solution $\left(\mathrm{MgCl}_{2} ; 0.8 \mathrm{mM}\right)$ but, this time, a $\mathrm{NaBr}$ solution $(1: 1$ electrolyte; $4.04 \mathrm{mM})$ was used as the background solution. As done in the multitracer cases illustrated in the previous sections, the concentration measurements were performed at different outlet ports and at different times. Both multicomponent ionic transport experiments were performed at a seepage velocity of $\approx 5 \mathrm{~m} / \mathrm{d}$, which is still representative of strongly advection-dominated regimes.

Figure 9 summarizes the spatially integrated breakthrough curves as well as the time-integrated transverse profiles for the two cases of multicomponent ionic transport. The general shapes of these profiles are similar to the ones obtained for the multitracer experiments (Figures 2 and 7). Notice that, although the same electrolyte species was used as tracer in both experiments, the measured concentration profiles of the cation and the anion are significantly different because of the different background solutions. For the transport in pure water, $\mathrm{Mg}^{2+}$ and $\mathrm{Cl}^{-}$plumes tend to travel together as indicated by their practically identical temporal and spatial profiles despite the two have distinct diffusion coefficients (Table 1; Figures $9 \mathrm{a}$ and $9 \mathrm{~b})$. Since pure water (Milli-Q) is free of any major ions, the transported cation $\left(\mathrm{Mg}^{2+}\right.$ ) and anion $\left(\mathrm{Cl}^{-}\right)$are electrostatically forced to travel together in order to fulfill the charge balance of the system. In this case, the electromigration term (equations (13) and (15)) will provide a positive contribution and "speed up" the displacement of the less mobile cation $\left(\mathrm{Mg}^{2+}\right)$ and a negative contribution, slowing down the displacement of the more mobile anion $\left(\mathrm{Cl}^{-}\right)$. The hydrodynamic dispersion coefficients $\left(D_{L}, D_{T}\right)$ obtained by fitting the measured profiles for these two cases with the 1-D ADE model also provide very similar values for the two ions (for $\mathrm{Mg}^{2+}: D_{L}=4.33 \times 10^{-8} ; D_{T}=5.55 \times 10^{-9}$ and for $\mathrm{Cl}^{-}: D_{L}=4.13 \times$ $10^{-8} ; D_{T}=5.55 \times 10^{-9} \mathrm{~m}^{2} / \mathrm{s}$ ). 

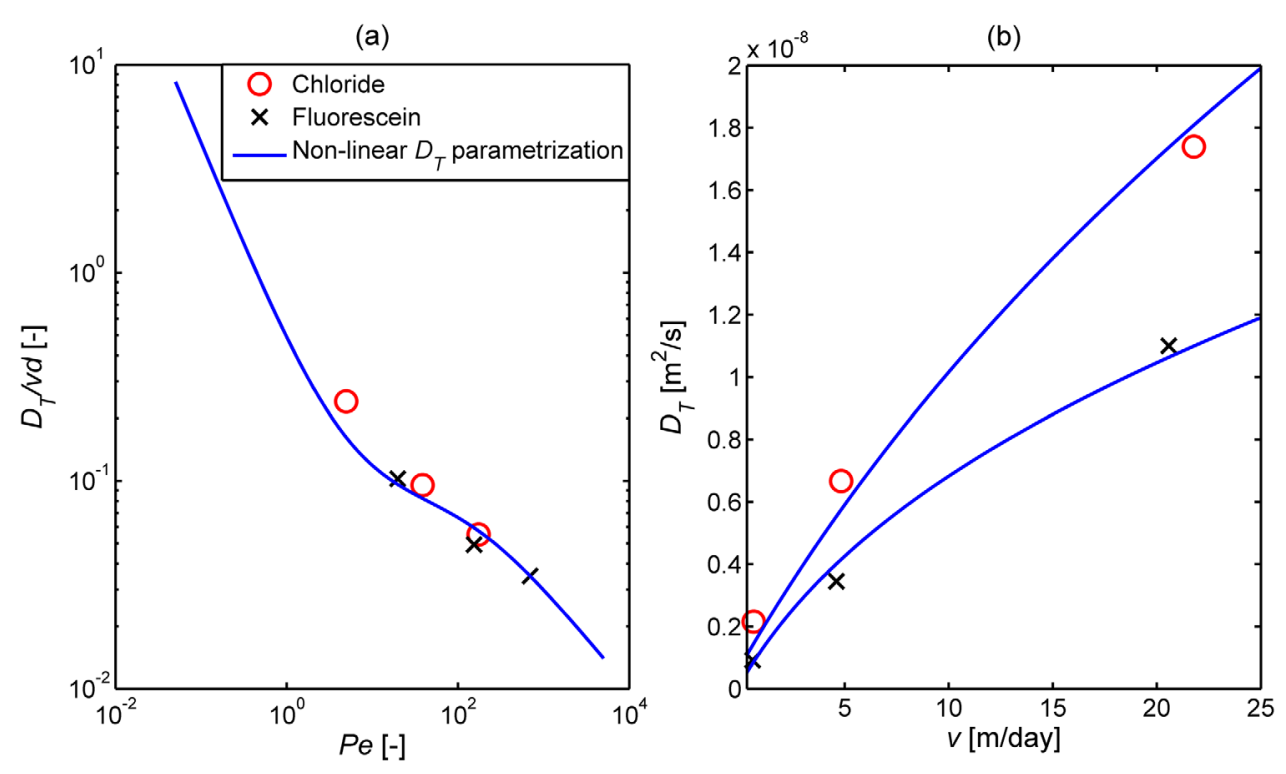

Figure 8. Comparison between the $D_{T}$ values computed from the measurements performed in this study (markers) and the predictions from the non-linear compound-specific parameterization, equation (18), (lines).

In contrast, when $\mathrm{MgCl}_{2}$ is injected in a $\mathrm{NaBr}$ background solution (with $\sim$ fivefold of the injected tracer concentration), the system is already charge-balanced by the background ions $\left(\mathrm{Na}^{+}\right.$and $\mathrm{Br}^{-}$). Hence, the plume ions $\left(\mathrm{Mg}^{2+}\right.$ and $\left.\mathrm{Cl}^{-}\right)$can migrate with mobilities close to their "self-diffusive/dispersive" properties without experiencing any noticeable electrostatic interaction. Thus, distinct profiles of the concentrations of these ions were measured at the outlet of the flow-through setup (Figures $9 \mathrm{c}$ and $9 \mathrm{~d}$ ). Fitting these profiles also resulted in distinct values of longitudinal and transverse hydrodynamic dispersion coefficients $D_{L}$ (for $\mathrm{Mg}^{2+}$ : $D_{L}=6.05 \times 10^{-8} ; D_{T}=4.20 \times 10^{-9} \mathrm{~m}^{2} / \mathrm{s}$ and for $\left.\mathrm{Cl}^{-}: D_{L}=3.78 \times 10^{-8} ; D_{T}=6.48 \times 10^{-9} \mathrm{~m}^{2} / \mathrm{s}\right)$.

Notice that in the second multicomponent ionic experiment, in which both longitudinal and transverse profiles became distinct, the same patterns discussed in the previous sections were observed: more peaked and less spread breakthrough curves for the more mobile species (in this cases $\mathrm{Cl}^{-}$), which, instead, show a more spread and less peaked profile in the lateral direction compared to the less mobile ion $\left(\mathrm{Mg}^{2+}\right)$. Although, accurately capturing transport processes of these ionic species requires either a detailed porescale model or a continuum model, with correct dispersion parameterizations (both longitudinal and transverse) accounting for all the relevant processes (e.g., species diffusion, flow-velocity, and the extent of incomplete mixing in the pores), here we attempt to predict the multicomponent transport of $\mathrm{MgCl}_{2}$ in pure water by using the overall dispersion parameters obtained from the case of transport in buffer electrolyte $(\mathrm{NaBr})$. This treatment is based on the assumption that in the presence of $\mathrm{NaBr}$ background solution, $\mathrm{Mg}^{2+}$ and $\mathrm{Cl}^{-}$travel exactly according to their self-diffusivities (i.e., as if charge-neutral species). Therefore, the values of $D_{L}$ and $D_{T}$ of these ions obtained from this case can be regarded as their "self-dispersion" coefficients. We considered these fitted "bulk dispersion" values as input parameters for the multicomponent ionic dispersion model (equation (17); section 3.4) to predict the coupled transport of $\mathrm{MgCl}_{2}$ in pure water. The magenta and green dotted lines in Figures $9 \mathrm{a}$ and $9 \mathrm{~b}$ refer to the predicted concentration profiles from the 2-D multicomponent ionic transport simulations, which show a very good agreement with the measurements and the fitted 1-D profiles.

The 2-D multicomponent ionic transport model enables us to effectively visualize the electrostatic interactions by mapping the spatial distributions of different flux components (equation (13): $J_{\text {tot }}=J$ dis $+J_{\text {mig }}$ ). In Figure 10, we illustrate the behavior for the case of transport of $\mathrm{MgCl}_{2}$ in pure water. The top two rows represent the longitudinal flux components (Figures 10a-10f), whereas the remaining bottom plots refer to the transverse flux components (Figures $10 \mathrm{~g}-10 \mathrm{l}$ ) after $t=50,150$, and 250 min of simulation. 
(a) Breakthrough Curves

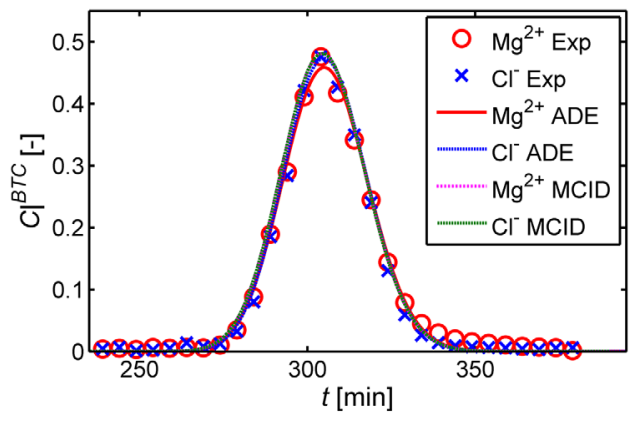

$\mathrm{MgCl}_{2}$ in Pure Water

(b) Transverse Profiles (c) Breakthrough Curves

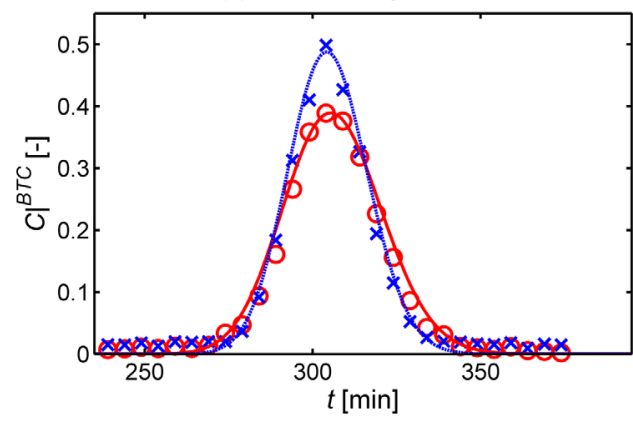

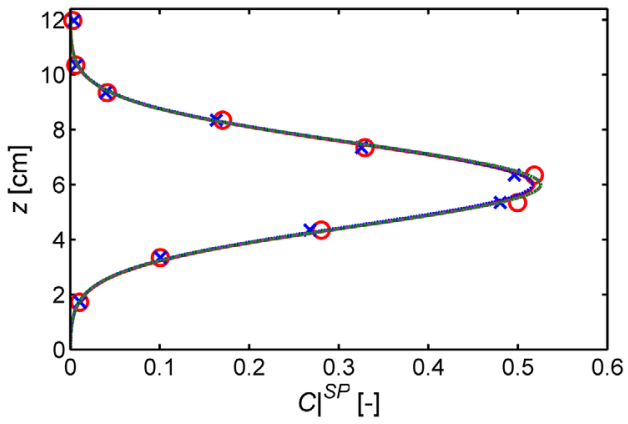

(b) Transverse Profiles

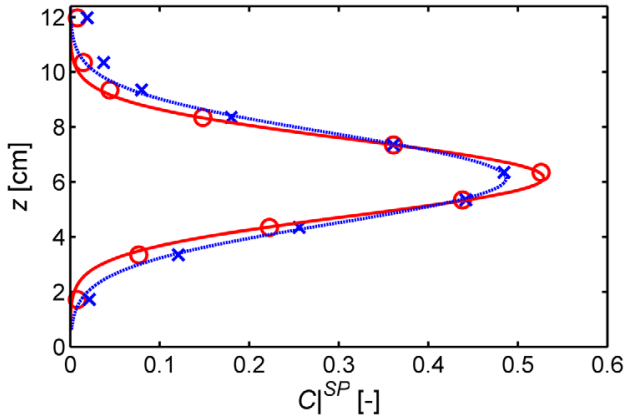

Figure 9. ( $a$ and $c$ ) Integrated breakthrough curves and ( $b$ and d) vertical concentration profiles during transport of $\mathrm{MgCl}_{2}$ in ( $a$ and $b$ ) pure water and ( $c$ and $d$ ) in $\mathrm{NaBr}$ background solution. The markers indicate the measured quantities whereas the lines represent the (solid lines) fitted profiles with 1-D ADE model and (dotted lines) the simulated profiles with the 2-D multicomponent ionic transport model.

It is interesting to notice that, although both $\mathrm{Mg}^{2+}$ and $\mathrm{Cl}^{-}$have identical overall distributions of total fluxes $\left(J_{\text {tot }}\right)$ (left column plots), the different components of $J_{\text {tot }}$ are distinct because of the variation in the "selfdispersion" coefficients of the different species. For transverse fluxes, $J_{\text {dis }}$ values are higher for $\mathrm{Cl}^{-}$compared to $\mathrm{Mg}^{2+}$, since $\mathrm{Cl}^{-}$has higher $D_{T}$ (Figures $10 \mathrm{~h}$ and $10 \mathrm{k}$ ). The situation is opposite in the longitudinal $J_{\text {dis }}$ distributions where $\mathrm{Mg}^{2+}$ apparently has a macroscopically higher $D_{L}$ (Figures $10 \mathrm{~b}$ and $10 \mathrm{e}$ ). The electrochemical migration flux components, $J_{\text {mig }}$ have the most interesting distributions with the cation $\left(\mathrm{Mg}^{2+}\right)$ and anion $\left(\mathrm{Cl}^{-}\right)$species showing similar pattern but opposite signs (right column plots). Such negative correlation facilitates an enhancement in the total flux for the less mobile species, and a reduction for the more mobile species, respectively. Thus, the electrostatic potential gradient couples the positively and negatively charged species leading to practically identical concentration profiles.

\section{Conclusions}

The high-resolution flow-through experiments performed in this study provides first experimental evidence of compound-specific diffusion/dispersion effects, as well as Coulombic interactions during multispecies transient transport in porous media, under advection-dominated conditions.

Furthermore, both the experimental and the simulation outcomes show that non-Fickian or "anomalous" transport, highlighting the impact of unresolved pore-scale heterogeneity, is observed in most cases even though the experimental domain was macroscopically "homogeneous". Our experiments also show that the sole analysis of integrated breakthrough curves may not provide an adequate portrayal of actual transport processes and can even lead to erroneous conclusions regarding mixing and plume dilution, especially under high flow velocities. We also show that experimentally determined entropy-based metrics, such as the flux-related dilution index, are useful to help distinguishing plume spreading from mixing.

The results of our experiments clearly highlight the importance of diffusion and electrochemical interactions on macroscopic solute transport. Perhaps due to the perception of the small scale at which these processes 
(a) Total Flux, $\mathrm{Mg}^{2+}$

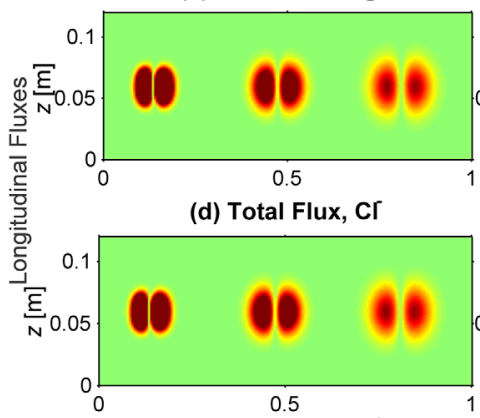

(g) Total Flux, $\mathrm{Mg}^{2+}$

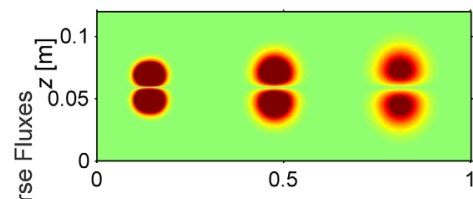

(j) Total Flux, Cr

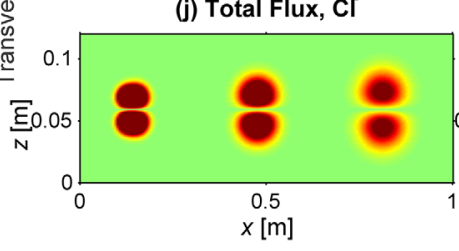

(b) Dispersive Flux, $\mathrm{Mg}^{2+}$

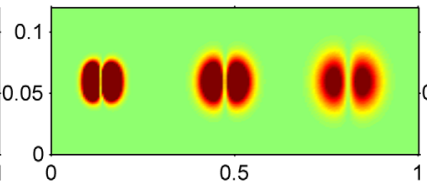

(e) Dispersive Flux, $\mathrm{Cl}^{-}$

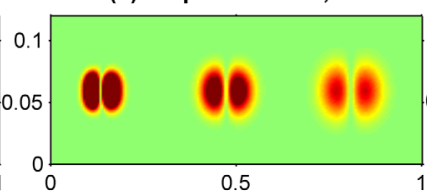

(h) Dispersive Flux, $\mathrm{Mg}^{2+}$

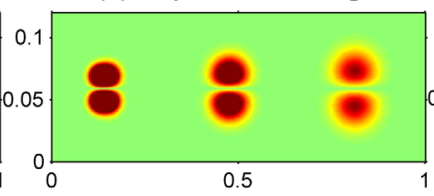

(k) Dispersive Flux, $\mathrm{Cl}^{-}$

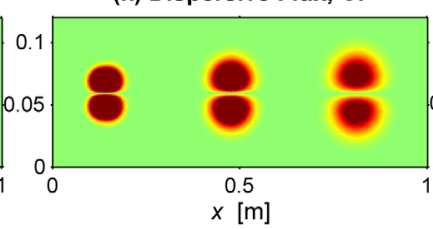

$\left[\mathrm{mmol} /\left(\mathrm{m}^{2} \cdot\right.\right.$ day $\left.)\right]$

(c) Electromigration Flux, $\mathrm{Mg}^{2+}$

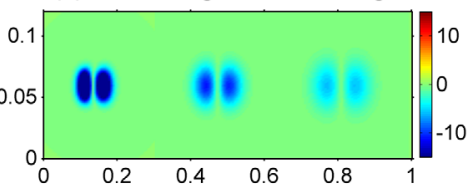

(f) Electromigration Flux, $\mathrm{CI}$

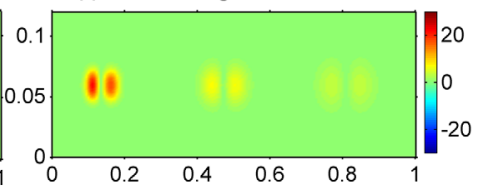

(i) Electromigration Flux, $\mathrm{Mg}^{2+}$

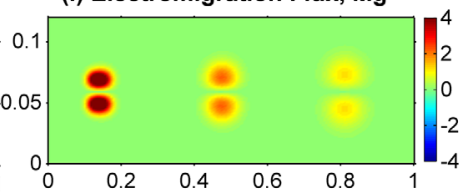

(I) Electromigration Flux, CI

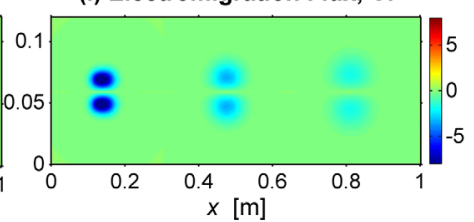

Figure 10. Maps of multicomponent ionic flux components in the (a-f) longitudinal and $(g-i)$ transverse direction for the transport of $\mathrm{MgCl}_{2}$ in pure water after $t=50,150$, and $250 \mathrm{~min}$. The direction from the core to the fringe of the plume is considered positive in the flux calculations.

occur and/or the small numerical values of the related coefficients, the study of these phenomena in advection-dominated flow-through systems has received only limited attention. Our results show that small-scale processes have an important influence on macroscopic transport behavior in porous media. These findings are relevant for advancing the understanding of solute transport in groundwater, which is often, inherently, a multispecies (i.e., compound-specific) and/or a multicomponent ionic transport problem (i.e., major ions and many dissolved contaminants are charged species). In our view, the outcomes of these experiments provide also a valuable data set for the development of modeling approaches. In fact, despite satisfactory results could be obtained by fitting different models to distinct experiment data, comprehensive frameworks able to consistently represent the macroscopic effects of small-scale interactions through the different conditions of flow velocity, compound-specific properties and electrostatic interaction need to be developed.

Our investigation was carried out considering conservative transport under simplified physical and chemical conditions. The extrapolation of these outcomes to more complex physically and chemically heterogeneous natural or engineered systems remains an open challenge. Furthermore, these experiments were performed in quasi 2-D setups and it is not clear, yet, how such effects will impact transient transport in fully 3-D domains, in which the role of diffusion and compound-specific mixing is quantitatively more significant [Ye al., 2015b], but also more complex flow topologies, resulting from physical heterogeneity and/or anisotropy [Ye et al., 2015c; Chiogna et al., 2014; Cirpka et al., 2015], may affect the behavior and magnitude of mixing as well as electrochemical migration. The expected increase in the availability of high-resolution investigations at different scales from microfluidic experiments [e.g., Zhang et al., 2010; de Anna et al., 2014], to laboratory (as the present study) and field-scale [e.g. Tuxen et al., 2006; Prommer et al., 2009], will provide unprecedented capabilities to understand and quantify small-scale subsurface processes. Furthermore, enhanced possibilities to resolve the small scale will lead to significant improvement in describing and properly upscaling the effects of diffusion and electromigration processes in multispecies, macroscopic transport in porous media. 


\section{CAGU Water Resources Research}

\section{Acknowledgments}

The experimental data for the concentration breakthrough measurements at the outlet of the flow-through setup are provided in the supporting information for the multitracer experiments (supporting information Table S2) and the multicomponent ionic experiments (supporting information Table S3). The description of the different model formulations used in this study is also presented in the supporting information (section S1). The document also provides the comparison of the simplified 1-D integrated breakthrough curves and vertical profiles with a 2-D analytical solution. The authors thank Jens Schaarup Sørensen for the assistance in establishing the experimental setup and the ion-chromatography measurements. We also thank Sinh Hy Nguyen and Mikael Emil Olsson for performing the ICP-MS measurements. M.R. and M.M. acknowledge the Baden-Württemberg Stiftung for the financial support of this research project by the Eliteprogram for Postdocs and M.R. also thanks the support of the German Research Foundation (grant RO 4169/2-1).

\section{References}

Appelo, C. A. J., and P. Wersin (2007), Multicomponent diffusion modeling in clay systems with application to the diffusion of tritium, iodide, and sodium in opalinus clay, Environ. Sci. Technol., 41(14), 5002-5007.

Appelo, C. A. J., A. Vinsot, S. Mettler, and S. Wechner (2008), Obtaining the porewater composition of a clay rock by modeling the in- and out-diffusion of anions and cations from an in-situ experiment, J. Contam. Hydrol., 101(1-4), 67-76.

Bard, A. J., and L. R. Faulkner (2001), Electrochemical Methods: Fundamentals and Applications, 2nd ed., 833 pp., John Wiley, New York.

Bear, J., and Y. Bachmat (1967), A generalized theory on hydrodynamic dispersion in porous media, in IASH Symposium on Artificial Recharge and Management of Aquifers, IASH Publ. 72, pp. 7-16, Int. Union Geod. Geophys., Haifa, Israel.

Ben-Yaakov, S. (1972), Diffusion of sea water ions-I. Diffusion of sea water into a dilute solution, Geochim. Cosmochim. Acta, 36(12), 1395-1406.

Berkowitz, B., and H. Scher (2009), Exploring the nature of non-Fickian transport in laboratory experiments, Adv. Water Resour., 32(5), 750-755.

Berkowitz, B., A. Cortis, M. Dentz, and H. Scher (2006), Modeling non-Fickian transport in geological formations as a continuous time random walk, Rev. Geophys., 44, RG2003, doi:10.1029/2005RG000178.

Bijeljic, B., A. H. Muggeridge, and M. J. Blunt (2004), Pore-scale modeling of longitudinal dispersion, Water Resour. Res., 40, W11501, doi: 10.1029/2004WR003567.

Boudreau, B. P. (1997), Diagenetic Models and Their Implementation: Modelling Transport And Reactions In Aquatic Sediments, 414 pp., Springer, Heidelberg.

Boudreau, B. P., F. J. R. Meysman, and J. J. Middelburg (2004), Multicomponent ionic diffusion in pore waters: Coulombic effects revisited, Earth Planet. Sci. Lett., 222(2), 653-666.

Cao, J., and P. K. Kitanidis (1998), Pore-scale dilution of conservative solutes: An example, Water Resour. Res., 34(8), 1941-1949, doi:10.1029/ 98WR01468.

Carrera, J., X. Sanchez-Vila, I. Benet, A. Medina, G. Galarza, and J. Guimera (1998), On matrix diffusion: Formulations, solution methods and qualitative effects, Hydrogeol. J., 6(1), 178-190.

Chiogna, G., and A. Bellin (2013), Analytical solution for reactive solute transport considering incomplete mixing within a reference elementary volume, Water Resour. Res., 49, 2589-2600, doi:10.1002/wrcr.20200.

Chiogna, G., C. Eberhardt, P. Grathwohl, O. A. Cirpka, and M. Rolle (2010), Evidence of compound-dependent hydrodynamic and mechanical transverse dispersion by multitracer laboratory experiments, Environ. Sci. Technol., 44(2), 688-693.

Chiogna, G., O. A. Cirpka, P. Grathwohl, and M. Rolle (2011), Relevance of local compound-specific transverse dispersion for conservative and reactive mixing in heterogeneous porous media, Water Resour. Res., 47, W07540, doi:10.1029/2010WR010270.

Chiogna, G., M. Rolle, A. Bellin, and O. A. Cirpka (2014), Helicity and flow topology in three-dimensional anisotropic porous media, Adv. Water Resour., 73, 134-143.

Cirpka, O. A., and P. K. Kitanidis (2000), An advective-dispersive stream tube approach for the transfer of conservative-tracer data to reactive transport, Water Resour. Res., 36(5), 1209-1220.

Cirpka, O. A., E. O. Frind, and R. Helmig (1999a), Numerical methods for reactive transport on rectangular and streamline-oriented grids, Adv. Water Resour., 22(7), 711-728.

Cirpka, O. A., E. O. Frind, and R. Helmig (1999b), Streamline-oriented grid generation for transport modelling in two-dimensional domains including wells, Adv. Water Resour., 22(7), 697-710.

Cirpka, O. A., F. P. J. de Barros, G. Chiogna, M. Rolle, and W. Nowak (2011), Stochastic flux-related analysis of transverse mixing in twodimensional heterogeneous porous media, Water Resour. Res., 47, W06515, doi:10.1029/2010WR010279.

Cirpka, O. A., G. Chiogna, M. Rolle, and A. Bellin (2015), Transverse mixing in three-dimensional nonstationary anisotropic heterogeneous porous media, Water Resour. Res., 51, 241-260, doi:10.1002/2014WR015331.

Coleman, T.F., and Y. Li (1996), An interior, trust region approach for nonlinear minimization subject to bounds, SIAM J. Optim., 6, $418-445$.

Cortis, A., and B. Berkowitz (2005), Computing "anomalous" contaminant transport in porous media: The CTRW MATLAB Toolbox, Ground Water, 43(6), 947-950.

Cussler, E. L. (2009), Diffusion: Mass Transfer in Fluid Systems, 3rd ed., 631 pp., Cambridge Univ. Press, Cambridge.

Davis, T., and I. Duff (1997), An unsymmetric-pattern multifrontal method for sparse LU factorization, SIAM J. Matrix Anal. Appl., 18(1), 140-158.

de Anna, P., J. Jimenez-Martinez, H. Tabuteau, R. Turuban, T. Le Borgne, M. Derrien, and Y. Méheust (2014), Mixing and reaction kinetics in porous media: An experimental pore scale quantification, Environ. Sci. Technol., 48, 508-516.

Delgado, J. M. P. Q. (2006), A critical review of dispersion in packed beds, Heat Mass Transf., 42(4), 279-310.

Dentz, M., T. Le Borgne, A. Englert, and B. Bijeljic (2011), Mixing, spreading and reaction in heterogeneous media: A brief review, J. Contam. Hydrol., 120-121, 1-17, doi:10.1016/j.jconhyd.2010.05.002.

Domenico, P. A., and V. V. Palciauskas (1982), Alternative boundaries in solid waste management, Ground Water, 20(3), 303-311.

Edery, Y., H. Sher, and B. Berkowitz (2009), Modeling bimolecular reactions and transport in porous media, Geophys. Res. Lett., 36, L02407, doi:10.1029/2008GL036381.

Felmy, A. R., and J. H. Weare (1991), Calculation of multicomponent ionic-diffusion from zero to high-concentration I. The system Na-K-Ca$\mathrm{Mg}-\mathrm{Cl}-\mathrm{SO}_{4}-\mathrm{H}_{2} \mathrm{O}$ at 25-Degrees-C, Geochim. Cosmochim. Acta, 55(1), 113-131.

Fiori, A., I. Jankovic, and G. Dagan (2011), The impact of local diffusion upon mass arrival of a passive solute in transport through threedimensional highly heterogeneous aquifers, Adv. Water Resour., 34(12), 1563-1573.

Giambalvo, E. R., C. I. Steefel, A. T. Fisher, N. D. Rosenberg, and C. G. Wheat (2002), Effect of fluid-sediment reaction on hydrothermal fluxes of major elements, eastern flank of the Juan de Fuca Ridge, Geochim. Cosmochim. Acta, 66(10), 1739-1757.

Gorelick, S. M., G. Liu, and C. Zheng (2005), Quantifying mass transfer in permeable media containing conductive dendritic networks, Geophys. Res. Lett., 32, L18402, doi:10.1029/2005GL023512.

Gramling, C. M., C. F. Harvey, and L. C. Meigs (2002), Reactive transport in porous media: A comparison of model prediction with laboratory visualization, Environ. Sci. Technol., 36(11), 2508-2514.

Guedes de Carvalho J. R. F., and J. M. P. Q. Delgado (2005), Overall map and correlation of dispersion data for flow through granular packed beds, Chem. Eng. Sci., 60, 365-375, doi:10.1016/j.ces.2004.07.121.

Gvirtzman, H., and S. M. Gorelick (1991), Dispersion and advection in unsaturated porous media enhanced by anion exclusion, Nature, 352 , 793-795. 
Haberer, C. M., M. Rolle, S. Liu, O. A. Cirpka, and P. Grathwohl (2011), A high-resolution non-invasive approach to quantify oxygen transport across the capillary fringe and within the underlying groundwater, J. Contam. Hydrol., 122(1-4), 26-39.

Haberer, C. M., M. Rolle, O. A. Cirpka, and P. Grathwohl (2012), Oxygen transfer in a fluctuating capillary fringe, Vadose Zone J., 11(3).

Hadley, P. W., and C. Newell (2014), The new potential for understanding groundwater contaminant transport, Groundwater, 52(2), 174-186.

Haggerty, R., and S. M. Gorelick (1995), Multiple-rate mass-transfer for modeling diffusion and surface-reactions in media with pore-scale heterogeneity, Water Resour. Res., 31(10), 2383-2400.

Heidari, P., and L. Li (2014), Solute transport in low-heterogeneity sandboxes: The role of correlation length and permeability variance, Water Resour. Res., 50, 8240-8264, doi:10.1002/2013WR014654.

Hochstetler, D. L., M. Rolle, G. Chiogna, C. M. Haberer, P. Grathwohl, and P. K. Kitanidis (2013), Effects of compound-specific transverse mixing on steady-state reactive plumes: Insights from pore-scale simulations and Darcy-scale experiments, Adv. Water Resour., 54, 1-10.

Kitanidis, P. K. (1994), The concept of the Dilution Index, Water Resour. Res., 30(7), 2011-2026.

Kosakowski, G., B. Berkowitz, and H. Scher (2001), Analysis of field observations of tracer transport in a fractured till, J. Contam. Hydrol., 47(1), 29-51, doi:10.1016/S0169-7722(00)00140-6.

LaBolle, E. M., and G. E. Fogg (2001), Role of molecular diffusion in contaminant migration and recovery in an alluvial aquifer system, Transp. Porous Med., 42(1-2), 155-179.

Lasaga, A. C. (1979), The treatment of multi-component diffusion and ion pairs in diagenetic fluxes, Am. J. Sci., 279(3), 324-346.

Lasaga, A. C. (1998), Kinetic Theory in the Earth Sciences, 811 pp., Princeton Univ. Press, Princeton, N. J.

Le Borgne, T., M. Dentz, P. Davy, D. Bolster, J. Carrera, J. de Dreuzy, and O. Bour (2011), Persistence of incomplete mixing: A key to anomalous transport, Phys. Rev. E, 84, 015301

Leij, F. J., T. H. Skaggs, and M. T. Van Genuchten (1991), Analytical solutions for solute transport in three-dimensional semi-infinite porous media, Water Resour. Res., 27(10), 2719-2733.

Liu, C. X. (2007), An ion diffusion model in semi-permeable clay materials, Environ. Sci. Technol., 41(15), 5403-5409.

Liu, C. X., J. Shang, and J. M. Zachara (2011), Multispecies diffusion models: A study of uranyl species diffusion, Water Resour. Res., 47, W12514, doi:10.1029/2011WR010575.

Luo, J., O. A. Cirpka, W. Wu, M. N. Fienen, P. M. Jardine, T. L. Mehlhorn, D. B. Watson, C. S. Criddle, and P. K. Kitanidis (2005), Mass-transfer limitations for nitrate removal in a uranium-contaminated aquifer, Environ. Sci. Technol., 39(21), 8453-8459.

Luo, J., M. Dentz, O. A. Cirpka, and P. K. Kitanidis (2007), Breakthrough curve tailing in a dipole flow field, Water Resour. Res., 43, W09403, doi:10.1029/2006WR005600.

Molins, S., D. Trebotich, C. I. Steefel, and C. P. Shen (2012), An investigation of the effect of pore scale flow on average geochemical reaction rates using direct numerical simulation, Water Resour. Res., 48, W03527, doi:10.1029/2011WR011404.

Muniruzzaman, M., and M. Rolle (2015), Impact of multicomponent ionic transport on $\mathrm{pH}$ fronts propagation in saturated porous media, Water Resour. Res., 51, 6739-6755, doi:10.1002/2015WR017134.

Muniruzzaman, M., and M. Rolle (2016), Modeling multicomponent ionic transport in groundwater with IPhreeqc coupling: Electrostatic interactions and geochemical reactions in homogeneous and heterogeneous domains, Adv. Water Resour., 98, 1-15, doi:10.1016/ j.advwatres.2016.10.013.

Muniruzzaman, M., C. M. Haberer, P. Grathwohl, and M. Rolle (2014), Multicomponent ionic dispersion during transport of electrolytes in heterogeneous porous media: Experiments and model-based interpretation, Geochim. Cosmochim. Acta, 141, 656-669.

Porta, G. M., B. Bijeljic, M. J. Blunt, and A. Guadagnini (2015), Continuum-scale characterization of solute transport based on pore-scale velocity distributions, Geophys. Res. Lett., 42, 7537-7545, doi:10.1002/2015GL065423.

Prommer, H., B. Anneser, M. Rolle, F. Einsiedl, and C. Griebler (2009), Biogeochemical and isotopic gradients in a BTEX/PAH contaminant plume: Model-based interpretation of a high-resolution field data set, Environ. Sci. Technol., 43, 8206-8212, doi:10.1021/es901142a.

Raje, D. S., and V. Kapoor (2000), Experimental study of bimolecular reaction kinetics in porous media, Environ. Sci. Technol., 34, 1234-1239, doi:10.1021/es9908669.

Rolle, M., and P. K. Kitanidis (2014), Effects of compound-specific dilution on transient transport and solute breakthrough: A pore-scale analysis, Adv. Water Resour., 71, 186-199.

Rolle, M., C. Eberhardt, G. Chiogna, O. A. Cirpka, and P. Grathwohl (2009), Enhancement of dilution and transverse reactive mixing in porous media: Experiments and model-based interpretation, J. Contam. Hydrol., 110(3-4), 130-142.

Rolle, M., D. L. Hochstetler, G. Chiogna, P. K. Kitanidis, and P. Grathwohl (2012), Experimental investigation and pore-scale modeling interpretation of compound-specific transverse dispersion in porous media, Transp. Porous Med., 93(3), 347-362.

Rolle, M., G. Chiogna, D. L. Hochstetler, and P. K. Kitanidis (2013a), On the importance of diffusion and compound-specific mixing for groundwater transport: An investigation from pore to field scale, J. Contam. Hydrol., 153, 51-68.

Rolle, M., M. Muniruzzaman, C. M. Haberer, and P. Grathwohl (2013b), Coulombic effects in advection-dominated transport of electrolytes in porous media: Multicomponent ionic dispersion, Geochim. Cosmochim. Acta, 120, 195-205.

Sanchez-Vila, X., D. Fernàndez-Garcia, and A. Guadagnini (2010), Interpretation of column experiments of transport of solutes undergoing an irreversible bimolecular reaction using a continuum approximation, Water Resour. Res., 46, W12510, doi:10.1029/2010WR009539.

Scheidegger, A. E. (1961), General theory of dispersion in porous media, J. Geophys. Res., 66(10), 3273-3278.

Scheven, U. M. (2013), Pore-scale mixing and transverse dispersivity of randomly packed monodisperse spheres, Phys. Rev. $E, 110(21)$ 214504, doi:10.1103/PhysRevLett.110.214504

Steefel, C. I., and K. Maher (2009), Fluid-rock interaction: A reactive transport approach, Rev. Mineral. Geochem., 70, 485-532.

Tartakovsky, A. M., G. D. Tartakovsky, and T. D. Scheibe (2009), Effects of incomplete mixing on multicomponent reactive transport, Adv Water Resour., 32(11), 1674-1679, doi:10.1016/j.advwatres.2009.08.012.

Thullner, M., P. Van Cappellen, and P. Regnier (2005), Modeling the impact of microbial activity on redox dynamics in porous media, Geochim. Cosmochim. Acta, 69(21), 5005-5019.

Tuxen N., H. J. Albrechtsen, and P. L. Bjerg (2006), Identification of a reactive degradation zone at a landfill leachate plume fringe using high-resolution sampling and incubation techniques. J. Contam. Hydrol., 85, 179-194.

Valocchi, A. J. (1985), Validity of the local equilibrium assumption for modeling sorbing solute transport through homogeneous soils, Water Resour. Res., 21(6), 808-820.

Van Cappellen, P., and J.-F. Gaillard (1996), Biogeochemical dynamics in aquatic sediments, Rev. Mineral. Geochem., 34(1), 335-376.

van Genuchten, M. T., and P. J. Wierenga (1976), Mass transfer studies in sorbing porous media I. Analytical solutions 1, Soil Sci. Soc. Am. J., $40(4), 473-480$ 
van Genuchten, M. T., F. J. Leij, T. H. Skaggs, N. Toride, S. A. Bradford, and E. M. Pontedeiro (2013), Exact analytical solutions for contaminant transport in rivers 1. The equilibrium advection-dispersion equation, J. Hydrol. Hydromech., 61(2), 146-160.

Vinograd, J. R., and J. W. McBain (1941), Diffusion of electrolytes and of the ions in their mixtures, J. Am. Chem. Soc., 63(7), 2008-2015.

Willmann, M., J. Carrera, and X. Sanchez-Vila (2008), Transport upscaling in heterogeneous aquifers: What physical parameters control memory functions?, Water Resour. Res., 44, W12437, doi:10.1029/2007WR006531.

Worch, E. (1993), A new equation for the calculation of diffusion coefficients for dissolved substances, Vom. Wasser., 81, $289-297$.

Ye, Y., G. Chiogna, O. Cirpka, P. Grathwohl, and M. Rolle (2015a), Experimental investigation of compound-specific dilution of solute plumes in saturated porous media: 2-D vs. 3-D flow-through systems, J. Contam. Hydrol., 172, 33-47.

Ye, Y., G. Chiogna, O. A. Cirpka, P. Grathwohl, and M. Rolle (2015b), Experimental evidence of helical flow in porous media, Phys. Rev. Lett., 115(19), 194502

Ye, Y., G. Chiogna, O. A. Cirpka, P. Grathwohl, and M. Rolle (2015c), Enhancement of plume dilution in two-dimensional and threedimensional porous media by flow focusing in high-permeability inclusions, Water Resour. Res., 51, 5582-5602, doi:10.1002/ 2015 WR016962.

Zhang, C. Y., K. Dehoff, N. Hess, M. Oostrom, T. W. Wietsma, A. J. Valocchi, B. W. Fouke, and C. J. Werth (2010), Pore-scale study of transverse mixing induced caco3 precipitation and permeability reduction in a model subsurface sedimentary system, Environ. Sci. Technol., 44(20), 7833-7838. 